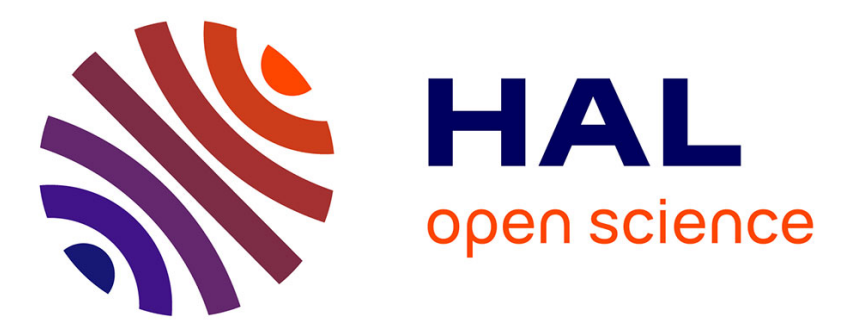

\title{
Crossed-beam universal-detection reactive scattering of radical beams characterized by laser-induced-fluorescence: the case of $\mathrm{C} 2$ and $\mathrm{CN}$
} Piergiorgio Casavecchia, Francesca Leonori, Kevin M. Hickson, Sébastien D. Le Picard, Xingan Wang, Raffaele Petrucci, Paolo Foggi, Nadia Balucani

\section{To cite this version:}

Piergiorgio Casavecchia, Francesca Leonori, Kevin M. Hickson, Sébastien D. Le Picard, Xingan Wang, et al.. Crossed-beam universal-detection reactive scattering of radical beams characterized by laserinduced-fluorescence: the case of C2 and CN. Molecular Physics, 2010, 108 (07-09), pp.1097-1113. 10.1080/00268971003657110 . hal-00596291

\section{HAL Id: hal-00596291 https://hal.science/hal-00596291}

Submitted on 27 May 2011

HAL is a multi-disciplinary open access archive for the deposit and dissemination of scientific research documents, whether they are published or not. The documents may come from teaching and research institutions in France or abroad, or from public or private research centers.
L'archive ouverte pluridisciplinaire HAL, est destinée au dépôt et à la diffusion de documents scientifiques de niveau recherche, publiés ou non, émanant des établissements d'enseignement et de recherche français ou étrangers, des laboratoires publics ou privés. 


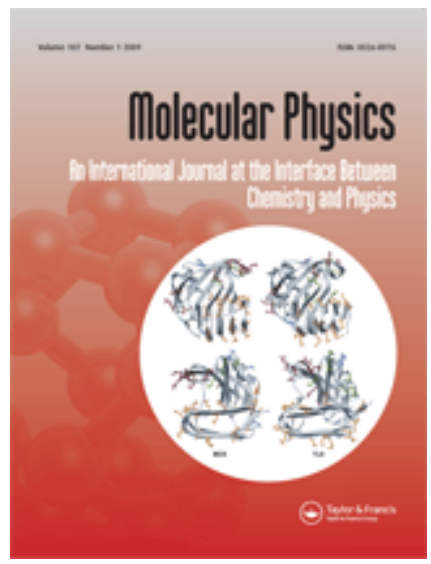

\section{Crossed-beam universal-detection reactive scattering of radical beams characterized by laser-induced-fluorescence: the case of $\mathrm{C} 2$ and $\mathrm{CN}$}

\begin{tabular}{|c|c|}
\hline Journal: & Molecular Physics \\
\hline Manuscript ID: & TMPH-2010-0017.R1 \\
\hline Manuscript Type: & Special Issue Paper - In honour of Prof Richard Zare \\
\hline $\begin{array}{r}\text { Date Submitted by the } \\
\text { Author: }\end{array}$ & 24-Jan-2010 \\
\hline Complete List of Authors: & $\begin{array}{l}\text { Casavecchia, Piergiorgio; Università degli Studi di Perugia, } \\
\text { Dipartimento di Chimica } \\
\text { Leonori, Francesca; Universita' degli Studi di Perugia, Dipartimento } \\
\text { di Chimica } \\
\text { Hickson, Kevin; Université de Bordeaux, Institut des Sciences } \\
\text { Moléculaires } \\
\text { Le Picard, Sébastien; University of Rennes 1, Institute de Physique } \\
\text { de Rennes } \\
\text { Wang, Xingan; Dalian Institute of Chemical Physics - Chinese } \\
\text { Academy of Sciences, State Key Laboratory of Molecular Reaction } \\
\text { Dynamics } \\
\text { Petrucci, Raffaele; Universita' degli Studi di Perugia, Dipartimento } \\
\text { di Chimica } \\
\text { Foggi, Paolo; Universita' degli Studi di Perugia, Dipartimento di } \\
\text { Chimica } \\
\text { Balucani, Nadia; Universita' degli Studi di Perugia, Dipartimento di } \\
\text { Chimica }\end{array}$ \\
\hline Keywords: & $\begin{array}{l}\text { Reaction dynamics, Laser induced fluorescence, Crossed molecular } \\
\text { beam technique, C2 and CN radicals, Reactions of CN radicals }\end{array}$ \\
\hline
\end{tabular}


Note: The following files were submitted by the author for peer review, but cannot be converted to PDF. You must view these files (e.g. movies) online.

New WinZip File.zip

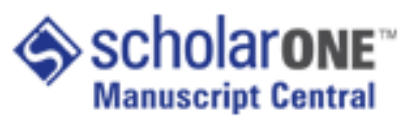

URL: http://mc.manuscriptcentral.com/tandf/tmph 


\title{
Crossed-beam universal-detection reactive scattering of radical beams characterized by laser-induced-fluorescence: the case of $\mathrm{C}_{2}$ and $\mathrm{CN}$
}

\author{
Francesca Leonori $^{\mathrm{a}}$, Kevin M. Hickson ${ }^{\mathrm{b}}$, Sébastien D. Le Picard ${ }^{\mathrm{c}}$, Xingan Wang ${ }^{\mathrm{d}}$, \\ Raffaele Petrucci ${ }^{\mathrm{a}}$, Paolo Foggi ${ }^{\mathrm{a}}$, Nadia Balucani ${ }^{\mathrm{a}}$, Piergiorgio Casavecchia ${ }^{\mathrm{a} *}$ \\ ${ }^{a}$ Dipartimento di Chimica, Università degli Studi di Perugia, Perugia, Italy \\ ${ }^{b}$ Institut des Sciences Moléculaires, UMR 5255 CNRS - Université de Bordeaux, 33405 Talence \\ Cedex, France \\ ${ }^{c}$ Institute de Physique de Rennes, UMR CNRS 6251, University of Rennes 1, Campus de Beaulieu, \\ 35042 Rennes Cedex, France \\ ${ }^{d}$ State Key Laboratory of Molecular Reaction Dynamics, Dalian Institute of Chemical Physics, \\ Chinese Academy of Sciences, Dalian, Liaoning 116023, P. R. China
}

\author{
Corresponding author: \\ Piergiorgio Casavecchia \\ Dipartimento di Chimica \\ Università degli Studi di Perugia \\ Via Elce di Sotto, 8 \\ 06123 Perugia \\ Italy \\ Phone: (+39) 0755855514 \\ Fax: (+39) 0755855606 \\ e-mail: piero@dyn.unipg.it
}

\begin{abstract}
We have generated continuous supersonic beams of dicarbon $\left(\mathrm{C}_{2}\right)$ and cyano $(\mathrm{CN})$ radicals by a highpressure radio-frequency discharge beam source starting from dilute mixtures in rare gases of suitable precursor molecules. We have subsequently characterized their internal quantum state distributions by laserinduced-fluorescence (LIF) in a new crossed molecular beam-laser apparatus. We have used these supersonic beams to study the reactive scattering of $\mathrm{C}_{2}$ and $\mathrm{CN}$ radicals with unsaturated hydrocarbons. We report here on the $\mathrm{C}_{2}$ and $\mathrm{CN}$ radical beam characterization by LIF and on dynamics studies of the reactions $\mathrm{CN}+\mathrm{C}_{2} \mathrm{H}_{2}$ (acetylene) and $\mathrm{CN}+\mathrm{CH}_{3} \mathrm{CCH}$ (methylacetylene) by the crossed molecular beam scattering technique with universal mass spectrometric detection and time-of-flight analysis. The role of $\mathrm{CN}$ rovibrational excitation on the dynamics of the $\mathrm{CN}+\mathrm{C}_{2} \mathrm{H}_{2}$ reaction is discussed with reference to previous dynamics and kinetics studies. These reactions are of interest in the chemistry of planetary atmospheres (Titan) and the interstellar medium as well as in combustion.
\end{abstract}

Keywords: reaction dynamics, laser induced fluorescence, crossed molecular beam technique, radical beams, $\mathrm{C}_{2}$ and $\mathrm{CN}$ radicals, reactions of $\mathrm{CN}$ with unsaturated hydrocarbons. 


\section{Introduction}

The field of gas-phase reaction dynamics aims to understand how chemical reactions occur at the microscopic level and has experienced an increasingly strong impact in many other areas of chemistry in recent years. Experimentally, studies of reaction dynamics are carried out under singlecollision conditions, which can be best obtained using molecular beams or pump-probe laser spectroscopic techniques [1]. Undoubtedly, central to the development of the field has been the "Crossed Molecular Beam" (CMB) scattering method with rotating electron-impact mass spectrometric (i.e., universal) detector and time-of-flight (TOF) analysis, as pioneered most notably by Lee and Herschbach in the late 1960s [2,3]. A further advance in our capability to investigate the dynamics of elementary reactions was made when, shortly afterwards, in the early 1970s, Zare and coworkers [4] introduced the complementary technique of Laser-Induced-Fluorescence (LIF) to the field, which permits us to probe, when applicable, the reaction products with single rotational quantum state resolution. The LIF technique proves also to be invaluable for characterizing the internal quantum state distributions of radical reactant beams [5]. Recently, in our laboratory we have used the LIF method to characterize the internal quantum state distributions of supersonic beams of $\mathrm{C}_{2}$ and $\mathrm{CN}$ radical reactants employed in $\mathrm{CMB}$ experiments with universal mass spectrometric detection.

The production of supersonic beams of stable gases or liquids/solids with an appreciable vapour pressure is a trivial procedure in reactive scattering experiments. In contrast, the production of beams composed of unstable atomic/radical species can be a more complicated procedure $[1,5]$. The radical production technique used in our laboratory is rather general and is based on a highpressure, high-power radio-frequency (RF) discharge beam source similar in design to that developed by Sibener et al. [6] for oxygen atoms. Atomic and molecular radicals are produced starting from dilute mixtures of suitable precursor molecules in a rare gas carrier. Here the discharge acts upon rare gas atoms at the tip of a quartz nozzle, promoting them to metastable 
states. These long-lived excited rare gas atoms subsequently initiate radical formation through collisions with the low concentration precursor molecules premixed in the bulk gas flow. In this way, we have been able to produce continuous supersonic beams [7] of a large variety of atomic such as $\mathrm{O}\left({ }^{3} \mathrm{P},{ }^{1} \mathrm{D}\right)[8,9,10], \mathrm{N}\left({ }^{4} \mathrm{~S},{ }^{2} \mathrm{D}\right)[11,12,13], \mathrm{C}\left({ }^{3} \mathrm{P},{ }^{1} \mathrm{D}\right)[14,15], \mathrm{Cl}\left({ }^{2} \mathrm{P}\right)[16,17]$, and $\mathrm{S}\left({ }^{3} \mathrm{P},{ }^{1} \mathrm{D}\right)$ $[18,19]$ - and molecular radicals - such as $\mathrm{OH}\left(X^{2} \Pi_{3 / 2,1 / 2}\right)[20], \mathrm{CN}\left(X^{2} \Sigma^{+}\right)[21]$ and $\mathrm{C}_{2}\left(X^{1} \Sigma_{\mathrm{g}}^{+}\right)$and $\mathrm{C}_{2}\left(a^{3} \Pi_{\mathrm{u}}\right)$ [22,23] (hereafter $\mathrm{C}_{2}\left(X^{1} \Sigma_{\mathrm{g}}^{+}\right)$and $\mathrm{C}_{2}\left(a^{3} \Pi_{\mathrm{u}}\right)$ will be indicated with ${ }^{1} \mathrm{C}_{2}$ and ${ }^{3} \mathrm{C}_{2}$, respectively)] and to study their reaction dynamics.

In $\mathrm{CMB}$ experiments using beams of stable molecules, the internal energy content of the reactants is usually very small because an extensive cooling of the internal degrees of freedom takes place during the supersonic expansion. However, when a discharge source is used for the production of transient species (such as molecular or atomic radicals), the cooling is almost certainly incomplete. As a result, the molecular radicals might be found in a range of vibrational, rotational and even electronic energy levels, while atomic radicals can be formed in electronically excited states. Given that these energetic radicals subsequently participate in reactive collisions, it is important to know how the excess energy is partitioned between the various internal modes because it can affect the reaction mechanism. Therefore, an accurate knowledge of the internal state distributions of the reactant species would significantly enhance the interpretation of the dynamical results in $\mathrm{CMB}$ experiments.

The population of the electronic and spin-orbit states of $\mathrm{O}, \mathrm{N}$ and $\mathrm{Cl}$ atoms, produced by our RF discharge beam source and previously used in CMB experiments, has been determined by SternGerlach magnetic analysis [7]. Since, after investigating the dynamics of reactions involving atomic species $[1,24,25,26]$ we have recently extended our reactive scattering studies to encompass reactions of molecular radicals (such as $\mathrm{C}_{2}$ and $\mathrm{CN}$ ) and also radical-radical reactions (such as $\mathrm{O}+$ allyl radical [27]), it is quite important to characterize the internal states of those molecular transient species. Recently, we have reported on CMB experiments on the reaction $\mathrm{C}_{2}+\mathrm{C}_{2} \mathrm{H}_{2}$ [22] which can play a role in hydrocarbon rich atmospheres, in the interstellar medium and in 
combustion chemistry. A peculiarity of $\mathrm{C}_{2}$, which is one of the simplest diatomic molecules (but in contrast to the similar $\mathrm{N}_{2}$ or $\mathrm{O}_{2}$ molecules it is highly reactive), is that the first electronically excited metastable state $\left(a^{3} \Pi_{\mathrm{u}}\right)$ lies only $610 \mathrm{~cm}^{-1}$ (or $7.3 \mathrm{~kJ} \mathrm{~mol}^{-1}$ ) above the ground state $\left(X^{1} \Sigma^{+}\right.$) [22]. $\mathrm{C}_{2}$ in both states is produced in the RF discharge beam source and both states can react with unsaturated hydrocarbons. As a consequence, to aid the interpretation of the data from scattering experiments on $\mathrm{C}_{2}$ reactions, we have concurrently initiated a series of experiments to characterize the rovibrational state populations and estimate the triplet-to-singlet ratio in the beams employed. We have already reported a first account of the LIF characterization of the rovibrational states of $\mathrm{C}_{2}\left(a^{3} \Pi_{\mathrm{u}}\right)[22]$. Here we present a full account of the LIF characterization of $\mathrm{C}_{2}\left(X^{1} \Sigma^{+}, a^{3} \Pi_{\mathrm{u}}\right)$ in our beams and report on the LIF characterization of continuous supersonic beams of CN radicals employed in CMB studies of the dynamics of the $\mathrm{CN}+\mathrm{C}_{2} \mathrm{H}_{2}$ and $\mathrm{CN}+\mathrm{CH}_{3} \mathrm{CCH}$ reactions. The CMB results on $\mathrm{CN}+\mathrm{C}_{2} \mathrm{H}_{2}$ and $\mathrm{CN}+\mathrm{CH}_{3} \mathrm{CCH}$ will also be reported.

There has been a long-standing interest in the reactions of $\mathrm{CN}$ radicals with hydrocarbons because of their relevance in combustion chemistry [28]. During the last few decades the reactions of $\mathrm{CN}$ radicals with hydrocarbons have attracted a renewed attention since they are considered a possible source of nitriles and cyanopolyynes in hydrocarbon and nitrogen rich atmospheres and in the interstellar medium [29,30,31]. These species have been observed in a variety of extraterrestrial environments (see [30,31] and references therein) - of particular interest is the atmosphere of Saturn's moon Titan, subject of the recent Cassini-Huygens mission -, and they are thought to be potential precursors of aminoacids and nucleobases in prebiotic chemistry [29]. Undoubtedly the $\mathrm{CN}$ radical is of major astrophysical importance and has been found to act as a tracer of the physical conditions of sources such as comets, stellar atmospheres, and the interstellar medium. CN radicals also play an important role in hydrocarbon-air flames [28,32] for the production of nitrogen oxides and other nitrogen containing pollutants.

The $\mathrm{CN}$ radical is often considered as a pseudohalogen because of the strong $\mathrm{C}-\mathrm{N}$ bond (748.0 $\mathrm{kJ} / \mathrm{mol}$ ) [33] and the large electron affinity (3.86 eV) [34]. As matter of fact, the $\mathrm{CN}$ bond behaves 
as a spectator in many reactions. An intriguing question, however, is whether internal excitation of $\mathrm{CN}$ has any effect on its reactivity, as recently pointed out in a kinetic study of the $\mathrm{CN}(\mathrm{v}=2$, $N)+\mathrm{C}_{2} \mathrm{H}_{2}$ reaction by Olkhov and Smith [35], or on the reaction mechanism. These issues have also been addressed in detailed studies by Macdonald and coworkers [36, 37] of the related reactions of $\mathrm{CN}$ with the saturated hydrocarbons $\mathrm{C}_{2} \mathrm{H}_{6}$ (ethane) and $\mathrm{CH}_{4}$ (methane), looking at the initial vibrational distribution of the HCN product by time resolved IR absorption spectroscopy in a flow reactor.

The kinetics [35,38,39,40,41,42,43,44,45] and dynamics [30,31,36,37,46,47,48,49,50,51,52] of the reactions of the $\mathrm{CN}$ radicals with hydrocarbons have been investigated extensively over the years. In particular, Smith, Sims and coworkers $[39,40]$ have measured rate constants down to very low temperature for a variety of $\mathrm{CN}$ reactions with unsaturated hydrocarbons and have found them to be very fast down to about $10 \mathrm{~K}$. Leone and coworkers [45] have used tunable VUV photoionization mass spectrometry for isomer specific product detection of $\mathrm{CN}$ reactions with ethene and propene. Suits and coworkers [46] have investigated the H-atom abstraction reactions of $\mathrm{CN}$ with alkanes (n-butane, $n$-pentane, $n$-hexane, cyclohexane) using the pulsed CMB technique with dc slice imaging, in which the alkyl radical products were detected via single photon ionization at $157 \mathrm{~nm}$. Kaiser and coworkers have investigate a wide variety of $\mathrm{CN}$ reactions with unsaturated hydrocarbons [30,31,47-52], including those with acetylene [47] and methylacetylene [48,49] using a pulsed CMB apparatus with electron-impact mass spectrometric detection. In those experiments, the $\mathrm{CN}$ beams were produced by the reaction of laser ablated species from a graphite rod with molecular nitrogen used as seeding gas [53]. Even though the $\mathrm{CN}$ internal population has not been directly characterized, $\mathrm{CN}$ radicals were inferred to be produced mostly in the ground vibrational state [53], while no information is available on the rotational states of CN. Because our beam conditions resulted in vibrationally excited CN (see Section 3), it may be of interest to compare our results with those of Kaiser and coworkers, at comparable collision energies, to assess the possible role of $\mathrm{CN}$ vibrational excitation in the $\mathrm{CN}+\mathrm{C}_{2} \mathrm{H}_{2}$ and $\mathrm{CN}+\mathrm{CH}_{3} \mathrm{CCH}$ reaction dynamics. 
According to recent $a b$ initio calculations [47,49], the reaction channels which are energetically allowed under the conditions of the present study are:

$$
\begin{aligned}
& \mathrm{CN}+\mathrm{HCCH} \quad \rightarrow \quad \mathrm{HCCCN}+\mathrm{H} \quad \Delta \mathrm{H}_{0}^{0}=-94 \mathrm{~kJ} \mathrm{~mol}^{-1} \\
& \rightarrow \quad \mathrm{HCCNC}+\mathrm{H} \quad \Delta \mathrm{H}^{0}{ }_{0}=+13 \mathrm{~kJ} \mathrm{~mol}^{-1} \\
& \rightarrow \quad \mathrm{HCN}+\mathrm{C}_{2} \mathrm{H} \quad \Delta \mathrm{H}_{0}^{0}=+23 \mathrm{~kJ} \mathrm{~mol}^{-1} \\
& \rightarrow \quad \mathrm{HNC}+\mathrm{C}_{2} \mathrm{H} \quad \Delta \mathrm{H}_{0}^{0}=+83 \mathrm{~kJ} \mathrm{~mol}^{-1} \\
& \mathrm{CN}+\mathrm{CH}_{3} \mathrm{CCH} \rightarrow \quad \mathrm{CH}_{3} \mathrm{CCCN}+\mathrm{H} \quad \Delta \mathrm{H}_{0}^{0}=-106 \mathrm{~kJ} \mathrm{~mol}^{-1} \\
& \rightarrow \quad \mathrm{CH}_{2} \mathrm{CCHCN}+\mathrm{H} \quad \Delta \mathrm{H}_{0}^{0}=-94 \mathrm{~kJ} \mathrm{~mol}^{-1} \\
& \rightarrow \quad \mathrm{CH}_{3}+\mathrm{HCCCN} \quad \Delta \mathrm{H}^{0}{ }_{0}=-132 \mathrm{~kJ} \mathrm{~mol}^{-1} \\
& \rightarrow \quad \mathrm{CH}_{3} \mathrm{CCNC}+\mathrm{H} \quad \Delta \mathrm{H}^{0}{ }_{0}=+8 \mathrm{~kJ} \mathrm{~mol}^{-1} \\
& \rightarrow \quad \mathrm{CH}_{2} \mathrm{CCHNC}+\mathrm{H} \quad \Delta \mathrm{H}^{0}{ }_{0}=+6 \mathrm{~kJ} \mathrm{~mol}^{-1} \\
& \rightarrow \quad \mathrm{HCN}+\mathrm{CH}_{2} \mathrm{CCH} \quad \Delta \mathrm{H}^{0}{ }_{0}=-170 \mathrm{~kJ} \mathrm{~mol}^{-1} \\
& \rightarrow \quad \mathrm{HNC}+\mathrm{CH}_{2} \mathrm{CCH} \quad \Delta \mathrm{H}^{0}{ }_{0}=-110 \mathrm{~kJ} \mathrm{~mol}^{-1}
\end{aligned}
$$

Our study of the $\mathrm{CN}+\mathrm{C}_{2} \mathrm{H}_{2}$ reaction was carried out at $\mathrm{E}_{\mathrm{c}}=48.1 \mathrm{~kJ} \mathrm{~mol}^{-1}$, which is considerably higher than those explored in the studies by Huang et al. [47] where $\mathrm{E}_{\mathrm{c}}$ was 21.1 and $27.0 \mathrm{~kJ} \mathrm{~mol}^{-1}$; hence our results extend the dynamical information to a wider range of collision energies. Regarding the $\mathrm{CN}+\mathrm{CH}_{3} \mathrm{CCH}$ reaction, our collision energy of $38.3 \mathrm{~kJ} \mathrm{~mol}^{-1}$ is only slightly higher than those $\left(\mathrm{E}_{\mathrm{c}}=13.4,24.7\right.$, and $\left.34.9 \mathrm{~kJ} \mathrm{~mol}^{-1}\right)$ explored by Balucani et al. [49], so that the results can be compared directly. In our experiments as well as in those by Kaiser and coworkers $[47,49]$, only the H-elimination channels could be observed for both systems. In the case of the reaction with acetylene, the $\mathrm{H}$ production channel was confirmed to be the only open channel in kinetic experiments $[43,44]$. Conversely, in the case of the reaction with methylacetylene, the $\mathrm{CH}_{3}$ elimination channel is probably important because in the similar reactions $\mathrm{CN}+\mathrm{CH}_{3} \mathrm{CHCH}_{2}$ [45] and $\mathrm{C}_{2} \mathrm{H}+\mathrm{CH}_{3} \mathrm{CCH}$ [54] the methyl loss was identified as a major reaction pathway. Interestingly, in the case of the reaction $\mathrm{CN}+\mathrm{CH}_{3} \mathrm{CHCH}_{2}$, the formation of $\mathrm{HCN}$ or $\mathrm{HNC}$ has not 
been observed [45], thus suggesting these two channels are minor in the reaction (2) as well, especially if one considers the augmented stability of the allyl radical produced in the reactions $\mathrm{CN}$ $+\mathrm{CH}_{3} \mathrm{CHCH}_{2} \rightarrow \mathrm{HCN} / \mathrm{HNC}+\mathrm{CH}_{2} \mathrm{CHCH}_{2}$ with respect to the $\mathrm{CH}_{2} \mathrm{CCH}$ radical produced in the channels $(2 \mathrm{f}, 2 \mathrm{~g})$.

This paper is organized as follows. In Section 2 we describe the LIF and CMB apparatuses. In Section 3 we report on the results of the LIF characterization of both $\mathrm{C}_{2}$ and $\mathrm{CN}$ beams. In Section 4 we report on the results of $\mathrm{CMB}$ experiments for both $\mathrm{CN}+\mathrm{C}_{2} \mathrm{H}_{2}$ and $\mathrm{CN}+\mathrm{CH}_{3} \mathrm{CCH}$ reactions and we discuss the possible role of the $\mathrm{CN}$ internal excitation in the scattering properties. Conclusions follow in Section 5.

\section{Experimental}

\section{a) LIF apparatus}

A dedicated apparatus consisting of two main parts has been built to perform LIF measurements on the radical beams. The LIF technique allows us to detect a wide range of radical species at the low concentrations typically used in the reactive scattering experiments. A schematic view of this apparatus is depicted in figure 1 . The first part of the system consists of a radiofrequency discharge radical source identical to the one employed in the $\mathrm{CMB}$ machine normally used for reactive scattering experiments; this source chamber is pumped by a Freon-baffled $8000 \mathrm{l} \mathrm{s}^{-1}$ diffusion pump backed by a $500 \mathrm{~m}^{3} \mathrm{~h}^{-1}$ roots pump. The resultant reactant beam is collimated using a boron-nitride skimmer (1.0 mm diameter) before passing into a main vacuum chamber (pumped by a Freonbaffled $24001 \mathrm{~s}^{-1}$ diffusion pump backed by a $35 \mathrm{~m}^{3} \mathrm{~h}^{-1}$ mechanical pump), where it is intercepted and probed by a tunable laser beam for LIF detection. The laser system consists of a pulsed (10 Hz), frequency tripled Nd YAG pump laser (Quanta System, HYL 101E) at $355 \mathrm{~nm}$ and a dye laser (Quanta System, D100). The laser propagates in the vacuum chamber at right angles to the radical beam and at about $5 \mathrm{~cm}$ from the front of the skimmer of the beam source chamber. The optical 
detection system consists of two convex lenses to collect and focus fluorescence onto the photocathode of a photomultiplier tube (THORN EMI, 9816 QB) and is placed at right angles to the plane containing the radical beam and the probe laser, $2.5 \mathrm{~cm}$ above the radical beam-laser beam crossing region (see figure 1). Care was taken to reduce sources of optical interference. Interference filters were employed to discriminate against scattered laser light and window fluorescence when necessary. Furthermore, window fluorescence was reduced to a minimum through the use of baffled side-arms containing the entrance and exit windows at about $0.7 \mathrm{~m}$ from the observation axis. Nevertheless, we were unable to eliminate the major source of scattered light which originated from the RF discharge source itself, resulting in poor signal-to-noise in some experimental spectra.

Continuous supersonic beams of $\mathrm{C}_{2}$ were generated by expanding a dilute mixture of $\mathrm{CO}(1.5 \%) / \mathrm{O}_{2}(0.8 \%) /$ rare gas $(\mathrm{He}$ or $\mathrm{Ne})$ at a pressure of $100 \mathrm{hPa}$ through a water-cooled quartz nozzle with a diameter of about $0.3 \mathrm{~mm}$, using a RF power of $300 \mathrm{~W}$. Both $\mathrm{C}$ atoms and $\mathrm{C}_{2}$ are produced in the discharge source, while no $\mathrm{C}_{3}$ is present under our experimental conditions, as determined from mass spectrometric analysis. $\mathrm{C}_{2}$ is expected to be produced in both the ground $X^{1} \Sigma_{\mathrm{g}}{ }^{+}$and first excited low-lying $a^{3} \Pi_{\mathrm{u}}$ electronic states. For the characterization of ${ }^{3} \mathrm{C}_{2}$ and ${ }^{1} \mathrm{C}_{2}$ present in the $\mathrm{C}_{2}$ beam the laser dyes Coumarin 503 and Coumarin 460, pumped by the frequency tripled Nd YAG laser at $355 \mathrm{~nm}$, were used to obtain tunable wavelengths in the ranges 484-541 nm and 442-490 nm for ${ }^{3} \mathrm{C}_{2}$ and ${ }^{1} \mathrm{C}_{2}$, respectively. For the ${ }^{1} \mathrm{C}_{2}$ experiments, the fundamental light from the Coumarin 460 dye was passed through a beta-barium borate (BBO) non-linear optical crystal, for second harmonic generation of wavelengths around $231 \mathrm{~nm}$. The determination of the population of the rovibrational levels of the ${ }^{3} \mathrm{C}_{2}$ and ${ }^{1} \mathrm{C}_{2}$ present in the $\mathrm{C}_{2}$ beam and an estimate of the triplet/singlet ratio are described in Section 3.

Continuous supersonic beams of $\mathrm{CN}$ were generated by expanding the precursor gas mixture of $\mathrm{CO}_{2}(0.8 \%) / \mathrm{N}_{2}(2.5 \%) / \mathrm{He}$ at a pressure of $100 \mathrm{hPa}$ through a water-cooled quartz nozzle with a diameter of about $0.3 \mathrm{~mm}$, using a RF power of $300 \mathrm{~W}$. For the characterization of the $\mathrm{CN}$ radical the laser dye Exalite 389 (Exciton), pumped by the frequency tripled Nd YAG laser at $355 \mathrm{~nm}$, was 
used in order to obtain tunable wavelengths in the range $384-390 \mathrm{~nm}$. An interference filter centred at $405 \mathrm{~nm}, 100 \mathrm{~nm}$ FWHM, was placed at the entrance of the photomultiplier tube to avoid saturation. The determination of the population of the ro-vibrational levels of the $\mathrm{CN}$ radical in its ground electronic state $X^{2} \Sigma^{+}$is described in Section 3. Electronically excited $\mathrm{CN}\left(A^{2} \Pi\right)$ and $\mathrm{CN}\left(B^{2} \Sigma^{+}\right)$, located $110 \mathrm{~kJ} \mathrm{~mol}^{-1}$ and $308 \mathrm{~kJ} \mathrm{~mol}^{-1}$ above the ground $X^{2} \Sigma^{+}$state [55], respectively, would decay to the ground state before reaching the laser (or secondary beam in the CMB experiments) at the interaction center. In fact, the radiative lifetimes of the $\mathrm{CN} B$ and $A$ states (v=0) are about 50-60 ns and $11 \mu$ s [55], respectively, which is shorter than the flight time (of about 25 $\mu \mathrm{s})$ of the fastest radical beams used.

\section{b) Reactive scattering experiments}

The crossed beam study of the reactions of $\mathrm{CN}$ radicals with methylacetylene and acetylene was carried out with a CMB apparatus equipped with an electron impact mass spectrometer (MS) for product detection. A detailed description of the apparatus can be found in other publications $[1,24,25]$ and only an outline will be given here. Figure 2 shows a schematic of the CMB apparatus. Two continuous supersonic beams of reactants are crossed at an angle of $90^{\circ}$ in a vacuum chamber; a pressure of $\sim 2 \times 10^{-6} \mathrm{hPa}$ in operating conditions ensures single collision conditions. Inside the reaction chamber, a three-stage differentially pumped detector (consisting of a quadrupole mass filter and a hot tungsten filament as electron source) can rotate in the plane of the beams in order to monitor the spatial distribution of the scattered particles; a time-of-flight (TOF) chopper wheel can be placed at the entrance of the detector to measure the particles velocity distribution. At least five scans per angle, with a counting time of $50 \mathrm{~s}$, were performed for the angular distributions of the possible reaction products, modulating the hydrocarbon beam with a tuning fork chopper at the frequency of $160 \mathrm{~Hz}$ for background subtraction. Velocity distributions (TOF spectra) of the reactants were determined by single-shot TOF analysis while those of the products were recorded at 
selected angles with the pseudo-random technique, the counting times ranging from 2 to 3 hours for the methylacetylene reaction, and from 40 to 90 minutes for the acetylene reaction.

The $\mathrm{CN}$ beam for the $\mathrm{CN}+\mathrm{C}_{2} \mathrm{H}_{2}$ experiments was generated by expanding the same precursor gas mixture $\mathrm{CO}_{2}(0.8 \%) / \mathrm{N}_{2}(2.5 \%) / \mathrm{He}$, as used in the LIF studies, at $150 \mathrm{hPa}$, the quartz nozzle diameter was $\varnothing \sim 0.3 \mathrm{~mm}$, and the RF power $300 \mathrm{~W}$; the resulting beam has a peak velocity of 2480 $\mathrm{m} \mathrm{s}^{-1}$ and speed ratio 8.3. For the hydrocarbon beam, $125 \mathrm{kPa}$ of pure acetylene were expanded through a stainless steel nozzle $(\varnothing=0.1 \mathrm{~mm})$ heated at about $750 \mathrm{~K}$; the beam had a peak velocity of $1117 \mathrm{~m} \mathrm{~s}^{-1}$ and speed ratio 6.2 . In these conditions the average collision energy is $\mathrm{E}_{\mathrm{c}}=48.1 \mathrm{~kJ}$ $\mathrm{mol}^{-1}[56]$ with a spread of about $30 \%$ (FWHM).

The $\mathrm{CN}$ beam for the $\mathrm{CN}+\mathrm{CH}_{3} \mathrm{CCH}$ experiments was generated by means of the $\mathrm{RF}$ discharge source mentioned above, by expanding the precursor gas mixture at a pressure of 55 mbar through a water-cooled quartz nozzle $(\varnothing \sim 0.5 \mathrm{~mm})$, with a RF power of $300 \mathrm{~W}$; the resulting beam has a peak velocity of $2079 \mathrm{~m} \mathrm{~s}^{-1}$ and speed ratio 5.5. The hydrocarbon beam was obtained by expanding 400 $\mathrm{hPa}$ of pure methylacetylene through a stainless steel nozzle $(\varnothing=0.1 \mathrm{~mm})$, and has a peak velocity of $741 \mathrm{~m} \mathrm{~s}^{-1}$ and speed ratio 4.2. In these conditions the average collision energy is $\mathrm{E}_{\mathrm{c}}=38.4 \mathrm{~kJ} \mathrm{~mol}^{-1}$; in this case the spread is about $50 \%$ (FWHM), which is larger than for the $\mathrm{CN}+\mathrm{C}_{2} \mathrm{H}_{2}$ system because of the lower beam speed ratios.

The quantities which are measured in a CMB experiment with MS/TOF detection are the product intensity as a function of the scattering angle - the laboratory angular distribution, $\mathrm{N}(\Theta)$ and the product intensity as a function of the scattering angle $\Theta$ and arrival time $\mathrm{t}$ - the time-offlight spectra, $\mathrm{N}(\Theta, \mathrm{t})$. The measurements are carried out in the laboratory (LAB) system of coordinates, but for the physical interpretation of the scattering data it is necessary to perform a coordinate transformation and move to the center-of-mass (CM) reference frame $[3,24,25]$. Because of the finite resolution of experimental conditions (angular and velocity spread of the reactant beams and angular resolution of the detector), the LAB to CM transformation is not single-valued and, therefore, analysis of the LAB data is usually performed by forward convoluting tentative CM 
distributions over the experimental conditions, including the energy dependence of the integral reactive cross section, which was taken to vary as $\mathrm{E}^{-1 / 3}$, i.e., the typical behaviour for barrierless reactions dominated by long-range attractive forces [57]. In the data analysis procedure, the product $\mathrm{CM}$ angular, $\mathrm{T}(\theta)$ and velocity (or translational energy) distributions $\left(\mathrm{P}\left(\mathrm{u}^{\prime}\right)\right.$ or $\mathrm{P}\left(\mathrm{E}_{\mathrm{T}}^{\prime}\right)$ ) are assumed, averaged and transformed to the LAB frame for comparison with the experimental distributions; the procedure is repeated until the best-fit of the experimental distributions is obtained. The product angular and translational energy distributions contain basic information. By measuring the product angular and velocity distributions, we can derive the amount of the total energy available to the products, $\mathrm{E}_{\text {Tот. }}$. We note that, because of the energy conservation rule, $\mathrm{E}_{\mathrm{TOT}}$ is given by ( $\mathrm{E}_{\mathrm{c}^{-}}$ $\Delta \mathrm{H}^{\circ}+\mathrm{E}_{\mathrm{INT}}$ ) where $\mathrm{E}_{\mathrm{c}}$ is the collision energy, $\Delta \mathrm{H}^{\circ}$ is the enthalpy of the reaction and $\mathrm{E}_{\mathrm{INT}}$ is the internal energy of the reactants. In CMB experiments the internal (rovibrational) energy of the stable molecules is relatively small when the beams are produced by expanding pure gases at room temperature because an extensive cooling of the internal degrees of freedom takes place during the supersonic expansion; however, when a plasma is used for the production of molecular radicals or unstable molecules like $\mathrm{C}_{2}$ and $\mathrm{CN}$ the cooling is not necessarily complete (see below) and $\mathrm{E}_{\mathrm{INT}}$ can give a sizeable contribution to the total energy.

\section{Results and Discussion: The LIF experiments}

\section{a) LIF characterization of the $C_{2}\left(a^{3} \Pi_{u}\right) /\left(X^{1} \Sigma_{g}^{+}\right)$beam}

We began the $\mathrm{C}_{2}$ beam characterization by looking at the rovibrational spectra of the triplet state of $\mathrm{C}_{2} \cdot{ }^{3} \mathrm{C}_{2}$ radicals were excited via the $(0,0),(1,1)$ and $(2,2)$ bands of the $\mathrm{d}^{3} \Pi_{\mathrm{g}}-\mathrm{a}^{3} \Pi_{\mathrm{u}}$ Swan system at $\sim 516.5,512.9$ and $509.8 \mathrm{~nm}$ respectively. Emission from the $\mathrm{d}^{3} \Pi_{\mathrm{g}}$ state with a lifetime of $\sim 100 \mathrm{~ns}[58]$ was observed in the $(0,1)(1,2)$ and $(2,3)$ bands at 563.6, 558.6 and $554.1 \mathrm{~nm}$ respectively. For the current measurements, two different interference filters were employed. The first one, centred at $560 \mathrm{~nm}$ with a FWHM of $10 \mathrm{~nm}$ and a transmission factor of 0.67 at the peak 
was primarily used to observe fluorescence originating from the ground and first excited vibrational states of ${ }^{3} \mathrm{C}_{2}$. The second one, centred at $550 \mathrm{~nm}$ with a FWHM of $20 \mathrm{~nm}$ and a transmission factor of 0.72 at the peak was used to observe fluorescence originating from the first and second excited vibrational states of ${ }^{3} \mathrm{C}_{2}$. In this way, it was possible to obtain estimates of the rotational temperatures and relative vibrational populations (and therefore the vibrational temperature) of the ${ }^{3} \mathrm{C}_{2}$ formed in the beams. For measurements of the rotational temperature of the vibrational states, the relative line intensities were corrected for the changing filter transmission profile across the band. Figure 3 panel (a) shows the experimental spectrum obtained for the $(0,0)$ band of the $d^{3} \Pi_{g}$ $\mathrm{a}^{3} \Pi_{\mathrm{u}}$ Swan system with helium as the carrier gas. Alongside the experimental spectra are presented the best fit simulations (see panel (b)) of the data using the Diatomic spectral simulation program [59] using previously published molecular constants for ${ }^{3} \mathrm{C}_{2}$ as input parameters [60]. These synthetic spectra allow us to determine rotational temperatures of approximately $250 \mathrm{~K}$ for the $(0$, 0) band of ${ }^{3} \mathrm{C}_{2}$ with helium as carrier gas (the rotational temperature is about $200 \mathrm{~K}$ when using $\mathrm{Ne}$ as carrier gas [22]). Similar results are also found for the $(1,1)$ and $(2,2)$ band spectra. For measurements of the relative vibrational populations, it was important to account for a normalisation factor for the probe laser assuming a linear relationship between the laser energy and the fluorescence intensity in addition to the filter transmission profile. Furthermore, it was also necessary to include the transition probabilities of both the excitation transition and the fluorescence step [61]. The usual procedure for obtaining estimates of the relative vibrational populations is to integrate the area under the same rotational lines in adjacent vibrational bands for several different lines to determine an average ratio. However this analysis was inappropriate for this system, due to low concentrations of ${ }^{3} \mathrm{C}_{2}$ in the molecular beam and significant overlap of spectral lines in the bandhead region of the experimental spectra. As the rotational temperatures of the vibrational bands are essentially equivalent for any particular carrier gas, better estimates of the relative populations were obtained by integrating the area under the entire $\mathrm{P}$ branch in each vibrational band after applying the various correction factors as described above. Furthermore, the wavelength range of 
each integrated band was carefully controlled so as to capture rotational levels up to and including $\mathbf{J}$ $=23$. In this way, the relative populations of the $\mathrm{v}=0,1$, and 2 levels have been determined to be 1 , 0.54 and 0.44 respectively. It is important to note that it is likely that R-branch lines from the $(0,0)$ and $(1,1)$ bands make small contributions to the relative populations of the $\mathrm{v}=1$ and $\mathrm{v}=2$ levels. Taking this into account leads us to estimate a vibrational temperature of $3500 \pm 750 \mathrm{~K}$ for the triplet state $\mathrm{C}_{2}$ in the molecular beam. This value was determined using the relative populations of the $\mathrm{v}=0$ and $\mathrm{v}=1$ bands; the $\mathrm{v}=2$ band population was somewhat too large for it to fit to the $3500 \mathrm{~K}$ distribution, so the error on the $\mathrm{v}=2$ population is of the order of $\pm 50 \%$. No experimental information could be obtained about the population of ( $v>2$ ) levels.

A similar characterization has been performed for the internal states of ${ }^{1} \mathrm{C}_{2}$ with helium and neon as carrier gases. In this case we have looked at the $(0,0),(1,1),(2,2)$ and higher transitions of the Mulliken $\left(\mathrm{D}^{1} \Sigma_{\mathrm{u}}{ }^{+}-\mathrm{X}^{1} \Sigma_{\mathrm{g}}{ }^{+}\right)$bands at approximately $231 \mathrm{~nm}$ (see figure 3 - panel $\mathrm{c}$ ). In this wavelength region, the vibrational bands of the singlet state coincide to a large extent, thus we have the opportunity to examine the relative populations of several bands in a single spectral scan. Unfortunately, the spectral region is also highly congested, making exact determinations more complex. However, several conclusions can be drawn from the spectral data. Examination of the Rbranch profile of the $(0,0)$ band of ${ }^{1} \mathrm{C}_{2}$ in helium, which is found to be reasonably uncongested, allows us to conclude that the rotational temperature obtained from the fit of $400 \mathrm{~K}$ is slightly higher than that found for ${ }^{3} \mathrm{C}_{2}$ in helium. From the best fit simulations of the experimental data (see figure 3 - panel d) it is clear that the relative vibrational populations are comparable to those obtained in the triplet state characterisation. Thus a vibrational temperature of $3500 \mathrm{~K}$ is also appropriate to describe the ${ }^{1} \mathrm{C}_{2}$ distribution. It should be noted that this vibrational temperature fits well the $(0,0)$ and $(1,1)$ bands, while no quantitative information was actually extracted from the $(2,2)$ band due to the band overlap. Furthermore, as the vibration bands are coincident in this wavelength region, the long wavelength end of the singlet spectrum shows that higher vibrational 


\section{b) LIF characterization of the CN radical beam}

When discharging $\mathrm{CO}$ (or $\mathrm{CO}_{2}$ ) / $\mathrm{N}_{2} / \mathrm{He}$ (or (Ne) gas mixtures, in addition to formation of $\mathrm{C}$ and $\mathrm{C}_{2}$ species, $\mathrm{CN}$ radicals are also produced. The mechanism leading to formation of $\mathrm{CN}$ is not clear, but presumably involves reactions of $\mathrm{C}$ atoms with molecular nitrogen (with one or both species in an electronically excited state), electronically excited atomic/molecular nitrogen with $\mathrm{CO}$ (or $\mathrm{CO}_{2}$ ) and/or $\mathrm{C}+\mathrm{N}$ recombination in the plasma before the supersonic expansion is completed. Because of the high energetic processes occurring in the hot plasma, we expect the $\mathrm{CN}$ radicals to be formed in highly excited rovibrational states, as well as in electronically excited states. While the electronically excited states decay to the ground electronic state because of their short lifetimes [55], the rotational excited states are not expected to be completely quenched because of the characteristics of the RF discharge source (hot plasma and moderate supersonic expansion), and the vibrational excited states are not expected to relax because of their large energy spacing. 
Characterization of the $\mathrm{CN}$ radicals was undertaken using LIF of a beam similar to the one used in the $\mathrm{CMB}$ experiments. Experiments were only performed on $\mathrm{CN} / \mathrm{He}$ beams due to the low signal levels for $\mathrm{CN} / \mathrm{Ne}$ mixtures (never used in $\mathrm{CMB}$ experiments). Slightly different expansion conditions and RF power proved not to affect significantly the internal quantum state distribution, so that the $\mathrm{CN}$ beams interrogated by LIF and those used in CMB experiments have very similar rovibrational distributions. We measured the rovibrational distribution of the ground electronic ${ }^{2} \Sigma^{+}$ state of CN primarily via the $(0,0),(1,1),(2,2)$ and $(3,3)$ bands of the $\mathrm{B}^{2} \Sigma^{+}-\mathrm{X}^{2} \Sigma^{+}$system at 387.7, 386.5, 385.5 and $384.7 \mathrm{~nm}$, respectively. The experimental spectrum recorded in the wavelength range of $384.0-388.5 \mathrm{~nm}$ is reported in figure 4(a), while an expanded view (from 386.5 to $388.5 \mathrm{~nm}$ ) is shown in figure $4(\mathrm{c})$. The experimental spectra were then simulated using the LIFBASE spectral simulation program [62]. The simulation also contained contributions from higher vibrational levels $(4 \leq v \leq 9)$ which fall in the $384-389 \mathrm{~nm}$ wavelength range in order to realistically reproduce the observed spectral lines. The simulations are reported in the figures 4(b) and (d).

The rotational distributions for low vibrational levels were clearly seen to be bimodal, as exemplified in figure 5(a) for the rotational distribution of $\mathrm{CN}(\mathrm{v}=0)$. A rotational temperature of approximately $250 \mathrm{~K}$, in fact, accounts for low rotational quantum numbers $(\mathrm{N}<10)$ with a peak in the population at $\mathrm{N}=6$. In contrast, the rotational populations in higher quantum numbers were found to exceed those of a thermalised distribution (at $250 \mathrm{~K}$, the rotational population falls to zero at $\mathrm{N} \sim 24$ ) with a minimum in the population at approximately $\mathrm{N}=22-28$. A second maximum in the population distribution was seen to occur at around $\mathrm{N}=39-44$ (corresponding to approximately $42 \mathrm{~kJ} \mathrm{~mol}^{-1}$ of rotational energy from the $v=0$ level), with peak values corresponding to a third of the primary maximum. The tail of the rotational distribution occurred at approximately $\mathrm{N}=60$ (corresponding to $82 \mathrm{~kJ} \mathrm{~mol}^{-1}$ ). It is worth noting that bimodal rotational distributions have also been obtained for $\mathrm{CN}$ radicals generated from photolysis of precursor molecules such as $(\mathrm{CN})_{2}, \mathrm{ClCN}$ and $\mathrm{BrCN}$, as used in the flow studies of Macdonald and coworkers 
[36,37]. Studies of rotational relaxation of high rotational levels of $\mathrm{CN}$, as produced for instance from the $\mathrm{BrCN}$ photolysis at $193 \mathrm{~nm}$, found that the initial $\mathrm{CN} \mathrm{N}$-levels relaxed to a $300 \mathrm{~K}$ Botzmann distribution (peaking at $\mathrm{N}=8$ ), and at one peaking near $\mathrm{N} \sim 65$, corresponding closely to the initial maximum in the $\mathrm{CN}(\mathrm{N})$ distribution [63]. It was observed that $\mathrm{N}$ states below $\mathrm{N} \sim 40$ were thermalized quickly, within a few gas kinetic collisions; however, for $\mathrm{N}>67$, these states are essentially metastable and very high $\mathrm{N}$ states were present even after a 1000 gas kinetic collisions with Ar or He. It was noted that other collision partners such as NO were much more efficient at relaxing these high $\mathrm{CN}(\mathrm{N})$ states. In our case similar effects are expected to occur, with expectedly somewhat more relaxation taking place because of the presence of molecular partners such as $\mathrm{CO}_{2} / \mathrm{CO}$ and $\mathrm{N}_{2}$, besides $\mathrm{He}$ (during the supersonic expansion, hundreds of collision take place).

Identical rotational distributions were used for all vibrational levels in the simulation due to the difficulty of fitting to the low signal to noise and congested wavelength region of the experimental spectrum. Nevertheless, the vibrational populations were found to be reasonably well described by a thermalised distribution (shown in figure 5(b)) with a vibrational temperature of $6500 \mathrm{~K}$. By analyzing the present experimental results, therefore, we can conclude that enough inelastic collisions occur upon exiting the discharge source to partially relax the $\mathrm{CN}$ rotational populations, whereas the vibrational populations remain largely unaffected and are seen to maintain a hot distribution.

\section{Results and Discussion: The crossed molecular beam experiments \\ a) $\quad \mathrm{CN}+\mathrm{C}_{2} \mathrm{H}_{2}$}

In figure 6 is shown the product laboratory angular distribution detected at $m / z=51$ (corresponding to the ion $\mathrm{C}_{3} \mathrm{HN}^{+}$) together with the relevant velocity vector ("Newton") diagram. The error bars (representing \pm 1 standard deviation) are also reported when they exceed the size of the dots indicating the intensity averaged over the different scans. In the Newton diagram of figure 6 are also shown the Newton circles relative to the two possible isomers HCCCN (channel 1a, 
dashed lines) and HCCNC (channel 1b, dotted lines) in the assumption that all the available energy is converted into product translational energy. The Newton circles delimit the LAB angular range within which each specific isomer can be scattered. The quite different exothermicities of the two channels imply a different extension of the Newton circles and of the relative scattering angular ranges. In figure 7 are shown the TOF spectra measured at selected angles. The LAB angular distribution is relatively narrow, but is characterized by a broad peak which is located slightly to the left of the center-of-mass angle $\left(\Theta_{\mathrm{CM}}=24.3^{\circ}\right)$. The TOF spectra are also relatively sharp and centered around the CM velocity (see figure 7). The solid lines in figures 6 and 7 represent the curves calculated with the best-fit functions depicted in figure 8 . The grey areas in figure 8 delimit the range of $\mathrm{CM}$ functions which still afford an acceptable fit of the data, i.e., they represent the error bars of the present determination. The best CM angular distribution (figure 8, top panel) exhibits a significant intensity in the whole angular range, with a marked preference for the forward hemisphere with a best-fit ratio $\mathrm{T}\left(180^{\circ}\right) / \mathrm{T}\left(0^{\circ}\right)$ of 0.66 . The best-fit ratio can vary by about \pm 0.10 within the error bars. This shape is consistent either with the competition of two reaction mechanisms (a direct one generating forward scattering and an indirect one generating a backwardforward symmetric angular distribution) or with the formation of a bound intermediate with a lifetime $\tau$ comparable to its rotational period $\tau_{\mathrm{R}}$ (osculating model of chemical reaction $[64,65,66]$ ). If the latter is the case, from the difference of the intensity at the two poles it is possible to give an estimate of the complex lifetime relative to its rotational period by means of the equation $\mathrm{T}\left(180^{\circ}\right) / \mathrm{T}\left(0^{\circ}\right)=\mathrm{e}^{-\tau_{\mathrm{R}} / 2 \tau}$, where $\mathrm{T}\left(0^{\circ}\right)$ and $\mathrm{T}\left(180^{\circ}\right)$ are the values assumed by $\mathrm{T}(\theta)$ at the two poles. With the observed asymmetry of the $\mathrm{CM}$ angular distribution, therefore, the $\tau / \tau_{\mathrm{R}}$ ratio is 1.2 . As far as the best-fit $\mathrm{P}\left(\mathrm{E}_{\mathrm{T}}{ }_{\mathrm{T}}\right)$ is concerned (figure 8 , bottom), we note that the peak is broad (extending from about 30 to $60 \mathrm{~kJ} \mathrm{~mol}^{-1}$ ) and quite displaced from $\mathrm{E}_{\mathrm{T}}{ }_{\mathrm{T}}=0$, which might indicate the presence of an exit barrier, but the $\mathrm{P}\left(\mathrm{E}_{\mathrm{T}}^{\prime}\right)$ show some intensity also at very small $\mathrm{E}_{\mathrm{T}}^{\prime}$ values. The fit of both angular and TOF distributions was very sensitive to the rise and the peak position, while it was less 
sensitive to the tail of the $\mathrm{P}\left(\mathrm{E}_{\mathrm{T}}^{\prime}\right)$, as clearly visible from the shape of the grey area. Nevertheless, it is quite clear that the extra amount of energy carried by the $\mathrm{CN}$ vibrational excitation is not needed to fit the experimental distributions (see the arrows in the bottom panel of figure 8 indicating the total available energy for the reaction involving the vibrationally excited states of $\mathrm{CN}$ ). The average product translational energy, defined as $\left\langle\mathrm{E}_{\mathrm{T}}^{\prime}\right\rangle=\sum \mathrm{P}_{\left(\mathrm{E}_{\mathrm{T}}\right)}^{\prime} \mathrm{E}_{\mathrm{T}}^{\prime} / \sum \mathrm{P}\left(\mathrm{E}_{\mathrm{T}}^{\prime}\right)$ is about $57 \mathrm{~kJ} \mathrm{~mol}^{-1}$ corresponding to a fraction of the total available energy, $\left\langle f_{T}\right\rangle=\left\langle E_{T}>/ E_{T O T}\right.$, of about 0.4 , where $E_{T O T}\left(=\mathrm{E}_{\mathrm{c}}-\Delta \mathrm{H}^{\circ}\right)$ is the one associated to the reaction of $\mathrm{CN}$ in its ground rovibrational level $(v=0$, $N=0$ ) leading to the more stable isomer HCCCN. The present experimental results are consistent with those obtained by Huang et al. [47] in pulsed CMB experiments at the lower collision energies of 21.1 and $27.0 \mathrm{~kJ} \mathrm{~mol}^{-1}$. At those lower $\mathrm{E}_{\mathrm{c}} \mathrm{s}$, the $\mathrm{CM}$ angular distributions already showed a less pronounced preference for forward scattering, in agreement with the trend predicted by the osculating model of chemical reaction with increasing $\mathrm{E}_{\mathrm{c}}$ [64-66]. Quite interestingly, at the lower $\mathrm{E}_{\mathrm{c}}$ investigated by Huang et al. the best-fit $\mathrm{T}(\theta)$ has a maximum around $\theta=60^{\circ}-95^{\circ}$ and that was taken as an evidence of a "bent displacement" of the $\mathrm{H}$ atom during the complex fission. Also the main characteristics of the best fit $\mathrm{P}\left(\mathrm{E}_{\mathrm{T}}{ }_{\mathrm{T}}\right)$ of Ref. [47] are consistent with the present determination with the $\left\langle f_{T}>\right.$ ranging from 0.33 to 0.36 . Nevertheless, an important difference with respect to the experiments of Huang et al. is that under the conditions of the present experiment, the formation of the $\mathrm{HCCNC}$ isomer is also possible. As a matter of fact, not only is the experimental $\mathrm{E}_{\mathrm{c}}$ sufficient to compensate for the endothermicity of that channel $\left(+13 \mathrm{~kJ} \mathrm{~mol}^{-1}\right)$, but it is also sufficient to overcome the exit barriers of +36 or $+19 \mathrm{~kJ} \mathrm{~mol}^{-1}$ which have been theoretically predicted along the two reaction pathways leading to $\mathrm{HCCNC}+\mathrm{H}$ (see figure 9 of Ref. [47]). In addition to the increased $\mathrm{E}_{\mathrm{c}}$, in our study the $\mathrm{CN}$ radical is also internally excited (see Section 3-b) with an average vibrational and rotational energy content of 41 and $16 \mathrm{~kJ} \mathrm{~mol}^{-1}$, respectively, so that $\mathrm{E}_{\mathrm{TOT}}$ is equal to $106 \mathrm{~kJ} \mathrm{~mol}^{-1}$. As a consequence, in our experiment we expect a contribution from channel (1b).

Quite interestingly, the initial vibrational excitation of the $\mathrm{CN}$ bond does not seem to influence the main reaction outcomes. This is witnessed by two facts: on one side there is no need 
to consider the extra amount of energy added by $\mathrm{CN}$ in $v=1-4$ even though the energy content of the vibrationally excited $\mathrm{CN}$ levels is quite sizable (e.g. $\Delta \mathrm{v}_{1-0}=24.4 \mathrm{~kJ} \mathrm{~mol}^{-1}, \Delta \mathrm{v}_{2-0}=48.6 \mathrm{~kJ} \mathrm{~mol}^{-1}$, $\left.\Delta \mathrm{v}_{3-0}=72.4 \mathrm{~kJ} \mathrm{~mol}^{-1}\right)$; on the other side, there is a strong similarity with the results by Huang et al. and it is known that the $\mathrm{CN}$ generated in their laser ablation beam source is produced mostly in the ground $v=0$ level. The lack of visible effects in the scattering functions due to the vibrational excitation of $\mathrm{CN}$ is not surprising, as the vibrational excitation is expected to promote a reaction when it affects a bond which is going to break during the reaction itself. Since the CN moiety is actually incorporated in the $\mathrm{HCCCN} / \mathrm{HCCNC}$ products, it is reasonable to expect that the vibrational excitation of the reactant will be maintained essentially as vibrational excitation of the molecular product. In other words it is not unexpected that the extra amount of energy available to the system when the reaction involves $\mathrm{CN}$ in one of the excited vibrational levels is not converted into product translational energy. Our interpretation is perfectly in line with that proposed by Smith and coworkers $[35,67]$ by analyzing the rate coefficients for the reaction $\mathrm{CN}+\mathrm{C}_{2} \mathrm{H}_{2}$ with $\mathrm{CN}$ in $\mathrm{v}=0$ and 2 at $\mathrm{T}=296 \mathrm{~K}$. The measured $k$ was $\sim 2.7 \times 10^{-10} \mathrm{~cm}^{3}$ molec $^{-1} \mathrm{~s}^{-1}$ irrespectively of the $\mathrm{CN}$ vibrational state, thus suggesting that vibrational excitation does not promote the reactivity. It is interesting to note that also the $\mathrm{CN}+\mathrm{C}_{2} \mathrm{H}_{6}$ and $\mathrm{CN}+\mathrm{CH}_{4}$ abstraction reactions were found to be essentially vibrationally adiabatic [36, 37]. In their studies Macdonald and coworkers [36,37] varied the initial vibrational population of the $\mathrm{CN}$ radical by using different precursor molecules for the $\mathrm{CN}$ radical source. For both reactions it was found that the initial $\mathrm{CN}(\mathrm{v})$ excitation did not appear as $\mathrm{HCN}$ excitation of the $\mathrm{C}-\mathrm{N}, \mathrm{HCN}\left(v_{1}, 0,0\right)$, or combination stretching vibrational levels, $\mathrm{HCN}\left(v_{1}, 0, v_{3}\right)$, in which the $\mathrm{C}-\mathrm{H}$ stretching motion is also excited (the bending $v_{2}$ could not be analyzed in those studies). In fact, the $\operatorname{HCN}\left(v_{1}, 0, v_{3}\right)$ vibrational levels were not significantly populated by the reaction, and hence, if the reaction is adiabatic in terms of the $\mathrm{CN}$ vibrational degree of freedom, then bending motion must also be excited along the $\mathrm{C}-\mathrm{N}$ stretching motion in the HCN product. Indeed, IR chemiluminescence studies by Copeland et al. [38] of $\mathrm{HCN}\left(v_{1}, v_{2}, v_{3}\right)$ formed from $\mathrm{CN}$ reactions with a variety of alkanes (including methane and ethane) found that the 
bend stretch combination levels of $\mathrm{HCN}$ were preferentially populated and not the pure $\mathrm{HCN}(0$, $\left.0, v_{3}\right)$ stretching manifold.

The effect of the $\mathrm{CN}$ rotational excitation is more difficult to predict and quantify. It is known that the rotational excitation of a reactant molecule can affect the reaction mechanism when the system follows direct dynamics and the transition state geometry is different from the geometry of the van der Waals complex formed in the entrance channel because of long range forces, as in the case of the $\mathrm{Cl}+\mathrm{H}_{2} / \mathrm{D}_{2} / \mathrm{HD}$ reactions $[16,17,68]$. Also, in the case of slightly endothermic reactions characterized by a potential energy barrier, such as $\mathrm{O}\left({ }^{3} \mathrm{P}\right)+\mathrm{HCl} \rightarrow \mathrm{OH}+\mathrm{Cl}$, a marked increase in reaction cross section with $\mathrm{HCl}$ rotation was observed by Zare and coworkers $[69,70]$. The effect is much more subtle when an exothermic reaction proceeds through the formation of a bound intermediate and without an entrance barrier (associated to a transition state), such as the reaction of interest here. For instance, in the case of the reaction $\mathrm{O}\left({ }^{1} \mathrm{D}\right)+\mathrm{H}_{2}$, the $\mathrm{OH}$ product rovibrational distributions have seen to be slightly different when the reactant $\mathrm{H}_{2}$ is in the ground or first excited rotational level [71]. Accurate quantum dynamical calculations for the barrierless reaction $\mathrm{C}\left({ }^{1} \mathrm{D}\right)+\mathrm{H}_{2}$ have shown small differences in the detailed shape of the $\mathrm{CM}$ angular distributions when the reacting $\mathrm{H}_{2}$ is in the ground and first excited rotational levels and also the value of the integral cross sections is slightly affected by the $\mathrm{H}_{2}$ rotational state $[15,72]$.

A very interesting experimental finding concerning the effect of $\mathrm{CN}$ rotation on the $\mathrm{CN}+\mathrm{C}_{2} \mathrm{H}_{2}$ reaction comes from the determination of the rate coefficients for the reaction of $\mathrm{CN}$ in various rotational levels of the $\mathrm{v}=2$ state $[35,67]$. In particular, the rate coefficients decrease from $7.9 \times 10^{-10} \mathrm{~cm}^{3}$ molec $^{-1} \mathrm{~s}^{-1}$ for $\mathrm{N}=0$ to $0.8 \times 10^{-10} \mathrm{~cm}^{3}$ molecule $\mathrm{s}^{-1}$ for $\mathrm{N}=20$, clearly indicating a minor capability of reacting for the higher rotational levels of $\mathrm{CN}$ in $\mathrm{v}=2$ [35]. As far as the reaction mechanism is concerned, we can conceive that a fast rotating $\mathrm{CN}$ radical can smear the preference for the C-side attack connected to the formation of the much more stable cis/trans-HCCHCN intermediates. This because the long-range forces that would orient the $\mathrm{CN}$ radical with the electron-density rich $\mathrm{C}$-side towards the $\pi$ system of acetylene are contrasted by the fast $\mathrm{CN}$ 
rotation. A resulting effect can be to enhance the HCCNC channel over the HCCCN one. Also, the increased internal energy content of the addition intermediates cis/trans-HCCHCN and cis/trans$\mathrm{HCCHNC}$ with respect to the experiments by Huang et al. (due both to the increase of $\mathrm{E}_{\mathrm{c}}$ and to the internal excitation of the $\mathrm{CN}$ radical) can significantly shorten the intermediate lifetimes. This in turn leads to a more pronounced bias for the forward scattering - as already commented on - and might impede the conversion of cis/trans-HCCHNC to cis/trans-HCCHCN which was predicted by RRKM calculations to be the most probable fate of the cis/trans-HCCHNC intermediates formed by the $\mathrm{CN}$ addition on the $\mathrm{N}$-side under the conditions of the experiments by Huang et al. In this respect, we note that the relatively fast rise of the best-fit $\mathrm{P}\left(\mathrm{E}_{\mathrm{T}}^{\prime}\right)$ can be taken as a hint that a second contribution associated to the endothermic channel leading to HCCNC is open. In fact, because of its endoergicity, the total available energy (for $\mathrm{CN}(\mathrm{v}=0, \mathrm{~N}=0)$ reaction) is only $35 \mathrm{~kJ} \mathrm{~mol}^{-1}$, that is $107 \mathrm{~kJ} \mathrm{~mol}^{-1}$ less than for the HCCCN forming channel. Hence, if the product translational energy distribution also peaks at about $30 \%$ of the total available energy, as in the case of the HCCCN channel, the maximum would occur at the quite low translational energy of $10 \mathrm{~kJ} \mathrm{~mol}^{-1}$, implying a fast rise of the $\mathrm{P}\left(\mathrm{E}_{\mathrm{T}}{ }_{\mathrm{T}}\right)$ distribution. As a matter of fact, during the best-fit procedure we have tried to simulate the experimental results by using two different contributions, one associated to the dominant HCCCN formation channel and one (accounting for roughly $10 \%$, with an upper bound of about 20\%) associated to the HCCNC formation. Nonetheless, since a satisfying fit could be obtained also when using a single set of CM functions, we have preferred not to report the double channel fit.

Notably, as discussed in the work of Macdonald and coworkers [36,37], particularly interesting is the effect of the high $\mathrm{CN}$ rotation whereby a correlation between rotational motion in the spectator diatom, $\mathrm{CN}$, and the bending motion of the product $\mathrm{HCN}$ molecule could rationalize the preference for the $\mathrm{HCN}$ product having bending excitation in the $\mathrm{CN}+\mathrm{C}_{2} \mathrm{H}_{6} / \mathrm{CH}_{4}$ reactions. Also in our case the high $\mathrm{CN}$ rotation could correlate with bending excitation of the HCCCN product. However, the $\mathrm{CN}+\mathrm{C}_{2} \mathrm{H}_{2}$ reaction proceeds via an addition mechanism with formation of a stable 
intermediate which then decomposes because of its high internal energy content, and therefore it is expected to follow a dynamics different than that of the $\mathrm{CN}+\mathrm{C}_{2} \mathrm{H}_{6}$ reaction, which is a direct abstraction reaction. Further experimental and theoretical effort will be needed to elucidate the extent of mode specificity in the $\mathrm{CN}+\mathrm{C}_{2} \mathrm{H}_{2}$ reaction.

In conclusion, the main characteristic of the scattering functions derived here are consistent with those derived by Huang et al. [43] at lower $\mathrm{E}_{\mathrm{c}}$. Since in their experiments the $\mathrm{CN}$ radical was produced mainly in the ground vibrational level, we can conclude that the $\mathrm{CN}$ vibrational excitation does not affect significantly the reactive scattering properties of the system, as expected because of the spectator nature of the $\mathrm{CN}$ bond. If there is an effect associated to the internal excitation of the $\mathrm{CN}$ radical, this is rather associated to the $\mathrm{CN}$ fast rotation which could partially enhance the minor HCCNC channel over the favoured HCCCN channel. Both observations are in line with the findings of previous kinetic experiments [35, 67].

\section{b) $\mathrm{CN}+\mathrm{CH}_{3} \mathrm{CCH}$}

Angular distribution and TOF spectra have been measured at the mass-to-charge ratio $m / z=65$ $\left(\mathrm{C}_{4} \mathrm{H}_{3} \mathrm{~N}^{+}\right)$, at the electron energy of $60 \mathrm{eV}$, to explore the H-elimination channels (2a) and (2b) for the reaction of $\mathrm{CN}$ radicals with methylacetylene. In an attempt to verify the occurrence of methyl elimination (2c), reactive signal has been recorded at $m / z=51 \quad\left(\mathrm{C}_{3} \mathrm{HN}^{+}\right)$and $50 \quad\left(\mathrm{C}_{3} \mathrm{~N}^{+}\right)$. Unfortunately, carbon atoms are present in large amounts in the $\mathrm{CN}$ beams and that means that both reactions of $\mathrm{C}$ and $\mathrm{CN}$ occur at the same time. The main channel of the $\mathrm{C}+\mathrm{CH}_{3} \mathrm{CCH}$ reaction is the one leading to $\mathrm{C}_{4} \mathrm{H}_{3}$ isomers which have the parent and an intense daughter peaks at $m / z=51\left(\mathrm{C}_{4} \mathrm{H}_{3}{ }^{+}\right)$ and $m / z=50\left(\mathrm{C}_{4} \mathrm{H}_{2}{ }^{+}\right)$, thus overlapping with the $\mathrm{CH}_{3} \mathrm{~N}$ and $\mathrm{C}_{3} \mathrm{~N}$ masses. Unfortunately, the signals recorded at $m / z=51$ and $m / z=50$ were essentially due to the $\mathrm{C}+\mathrm{CH}_{3} \mathrm{CCH}$ reaction and it was impossible to separate a contribution from the channel $(2 \mathrm{c})$ of the reaction $\mathrm{CN}+\mathrm{CH}_{3} \mathrm{CCH}$. As a matter of fact, certainly because of the different fragmentation patterns of $\mathrm{CH}_{3} \mathrm{~N}$ and $\mathrm{C}_{4} \mathrm{H}_{3}$, a small difference in the $m / z=51$ and $m / z=50$ distributions was visible thus suggesting that the contribution 
to the observed signal from the channel (2c) was not negligible. Further experiments, focusing on the distributions of the other daughter ions from $\mathrm{C}_{4} \mathrm{H}_{3}$ at masses different from those originating from $\mathrm{HCCCN}$, can possibly allow us to disentangle the contribution from channel (2c). The detection of the $\mathrm{HCN}$ or $\mathrm{HNC}$ products scattered by the $\mathrm{CH}_{2} \mathrm{CCH}$ co-product is particularly difficult because of the very unfriendly kinematics and was not attempted. Nevertheless, as already pointed out in the introduction, these channels are supposed to be minor by analogy with the $\mathrm{CN}+\mathrm{CH}_{3} \mathrm{CHCH}_{2}$ reaction [44].

Figure 9 shows the product laboratory angular distribution detected at $m / z=65$ together with the relevant velocity vector ("Newton") diagram. The error bars (representing \pm 1 standard deviation) are also reported when they exceed the size of the dots indicating the intensity averaged over the different scans. In the Newton diagram of figure 9 are also shown the Newton circles relative to the two possible isomers cyanomethylacetylene $\mathrm{CH}_{3} \mathrm{CCCN}$ (channel 2a, dashed lines) and cyanoallene $\mathrm{CH}_{2} \mathrm{CCHCN}$ (channel 2b, dotted lines) in the assumption that all the available energy is converted into product translational energy. The Newton circle associated to HCCCN scattered by $\mathrm{CH}_{3}$ (channel 2c) is also shown. In figure 10 are shown the TOF spectra measured at selected angles. The LAB angular distribution is relatively narrow, with a sharp peak in the proximity of the center-of-mass angle $\left(\Theta_{\mathrm{CM}}=28.7^{\circ}\right)$. The solid lines in figures 9 and 10 represent the curves calculated with the best-fit CM functions depicted in figure 11 . The grey areas in figure 11 delimit the range of CM functions which still afford an acceptable fit of the data. The best-fit CM angular distribution (figure 11, top) exhibits a significant intensity in the whole angular range, with some preference for sideways scattering with a peak around $100^{\circ}$. An isotropic $\mathrm{T}(\theta)$ still affords an acceptable fit of the experimental distributions as shown by the upper limit of the $T(\theta)$ error bars. The best-fit $\mathrm{P}\left(\mathrm{E}_{\mathrm{T}}^{\prime}\right)$ (figure 11 , bottom) is characterized by a peak around $30 \mathrm{~kJ} \mathrm{~mol}^{-1}$. The fit of both angular and TOF distributions was very sensitive to the rise and the peak position, while it was less sensitive to the tail of the $\mathrm{P}\left(\mathrm{E}_{\mathrm{T}}{ }_{\mathrm{T}}\right)$, as clearly visible from the shape of the grey area. The average product translational energy is about $43 \mathrm{~kJ} \mathrm{~mol}^{-1}$ corresponding to a fraction of the total available 
energy of about 0.30 when considering the reaction of $\mathrm{CN}$ in its ground rovibrational level $(v=0$, $N=0)$ leading to the more stable isomer $\mathrm{CH}_{3} \mathrm{CCCN}$.

The present experimental results are consistent with those obtained by Balucani et al. [49] in pulsed CMB experiments at the lower collision energies of $13.4,24.7$ and $34.9 \mathrm{~kJ} \mathrm{~mol}^{-1}$. At those lower $\mathrm{E}_{\mathrm{c}} \mathrm{s}$, the $\mathrm{CM}$ angular distributions are essentially isotropic, with a very small preference for forward scattering at the highest $\mathrm{E}_{\mathrm{c}}$ investigated and some propensity for sideways scattering in the other cases. As already commented on, an isotropic $\mathrm{CM} T(\theta)$ can still furnish a good fit of the present experimental distributions and, therefore, even though there is a more marked propensity for sideways scattering, the present experimental results overlap with the previous ones within the experimental uncertainties. Interestingly, since both the channels (2a) and (2b) contribute similarly to the reactive signal, as seen in $\mathrm{CMB}$ experiments using isotopically labelled $\mathrm{CD}_{3} \mathrm{CCH}$ [48], and since the decomposing transition state leading to cyanoallene has the right properties to explain sideways scattering (because there is a change from $s p^{3}$ to $s p^{2}$ hybridization of the carbon atom involved in the $\mathrm{C}-\mathrm{H}$ bond fission), a more pronounced preference for the sideways scattering can be taken as an evidence that in our experiments there is an increase of cyanoallene production.

The best-fit $\mathrm{P}\left(\mathrm{E}_{\mathrm{T}}{ }_{\mathrm{T}}\right)$ is very similar to those determined by Balucani et al.: in those cases as well, the peak position is around $30-40 \mathrm{~kJ} \mathrm{~mol}^{-1}$ and correspond to an average fraction of energy released as product translational energy of 0.30. Also for this system, therefore, the strong similarities in the $\mathrm{P}\left(\mathrm{E}_{\mathrm{T}}\right)$ characteristics of the two sets of experiments point to a negligible role of the $\mathrm{CN}$ vibrational excitation in determining the product energy release and this reaction can also be considered vibrationally adiabatic.

As for the reaction mechanism, the rotation of the $\mathrm{CN}$ radical can favour the $\mathrm{N}$-side attack to the $\pi$ orbitals of methylacetylene in this case as well, possibly leading to the isonitrile isomers. Unfortunately, in addition to the reaction enthalpies there is not much theoretical information on the channels (2d) and (2e), especially as far as possible exit barriers or easy pathways for the conversion between nitriles and isonitriles intermediates are concerned. In all cases, there are no 
apparent signs of their formation, neither in our experiments nor in the experiments of Balucani et al. [49] at similar $\mathrm{E}_{\mathrm{c}} \mathrm{s}$. As for other possible effects of the $\mathrm{CN}$ rotational excitation, a comparison of our results with those by Balucani et al. at the very similar $\mathrm{E}_{\mathrm{c}}$ of $34.9 \mathrm{~kJ} \mathrm{~mol}^{-1}$ might indicate that the $\mathrm{CN}$ high $N$ levels could enhance the sideways scattering, either by inducing a larger yield of the cyanoallene product or by affecting the total angular momentum associated to the reactive collision. In the case of the present experiments, in fact, a very low correlation between $\boldsymbol{L}$ and $\boldsymbol{L}^{\prime}$ is expected because of the significant contribution of the reactant rotational angular momentum. How this should produce more sideways scattering is, however, unclear.

\section{Conclusions}

In CMB experiments, when using supersonic molecular radical beams produced by means of a discharge source or produced during the expansion by a chemical reaction, care has to be taken with the characterisation of the internal rovibrational or electronic levels of the molecular radicals. In our laboratory we have pursued LIF characterization to determine the rovibrational distributions of the transient species $\mathrm{C}_{2}$ and $\mathrm{CN}$, produced in continuous supersonic beams by means of a separate RF discharge source which is identical to the one used in reactive scattering experiments. Because of the characteristics of the discharge beam source - which aims at limiting the radical recombination - the produced radicals undergo a limited number of relaxing collisions during the supersonic expansion and their rotational and, especially, vibrational distributions are not efficiently relaxed, leaving both diatomic species in excited levels.

Quite interestingly, both the reactions of $\mathrm{C}_{2}$ and $\mathrm{CN}$ with simple unsaturated hydrocarbons appear to be unaffected by the vibrational excitation of $\mathrm{C}_{2}$ and $\mathrm{CN}$. This is not surprising, at least for the case of the reactions $\mathrm{CN}+\mathrm{C}_{2} \mathrm{H}_{2}$ and $\mathrm{CN}+\mathrm{CH}_{3} \mathrm{CCH}$ and ${ }^{3} \mathrm{C}_{2}+\mathrm{C}_{2} \mathrm{H}_{2}$, because both $\mathrm{CN}$ and ${ }^{3} \mathrm{C}_{2}$ are not directly involved in the bond rearrangements leading from the reactant to the product species and they act as spectator. It is somewhat more surprising in the case of the ${ }^{1} \mathrm{C}_{2}+\mathrm{C}_{2} \mathrm{H}_{2}$ reaction $[22,73,74]$, because, according to the ab initio calculations of the relevant singlet potential 


\section{Acknowledgements}

We acknowledge financial support from the Italian MIUR (Ministero Istruzione Università Ricerca) under projects PRIN (2007-H9S8SW). This work has also been supported in the initial stages by the European Union Marie-Curie human resources and mobility programme, including post-doctoral fellowships for K. M. Hickson and X. Wang, under contract MCRTN-CT-2004-512302, Molecular Universe, and through the Coordination Action 001637 (Europlanet). R. Petrucci thanks FSE (Fondo Sociale Europeo)- Regione Umbria - Ministero del Lavoro e delle Politiche Sociali for a fellowship. We thank P. Sharkey, A. Paladini, R. Cireasa, M. Pasquini and R. Piani for their contribution in setting up the LIF system and E.B. Jochnowitz for help in the spectra simulations of $\mathrm{C}_{2}$. SDLP also acknowledges support from the French Agence Nationale de Recherche, Programme Blanc 'Cold reactions of neutral species, CRNS'. Finally, PC and SDLP acknowledge the Galileo Programme 2008/2009 between Perugia and Rennes. 


\section{FIGURE CAPTIONS}

Figure 1 Side-view of the laser induced fluorescence apparatus. C, L and G are capacitor, inductance and ground, respectively (see ref. 7). PMT: photomultiplier. (+) indicates the radical beam - laser beam interaction region.

Figure 2 Top-view of the crossed molecular beam apparatus with rotating mass spectrometric detector and time-of-flight chopper.

Figure $3 \quad \mathrm{C}_{2}\left(a^{3} \Pi_{\mathrm{u}}\right)$ laser induced fluorescence spectrum using the $(0,0)$ band of the $\left(d^{3} \Pi_{\mathrm{g}}\right.$ $\left.a^{3} \Pi_{\mathrm{u}}\right)$ Swan system with helium as carrier gas; panel (a): experimental spectrum; panel (b): the bestfit simulation (see text). $\mathrm{C}_{2}\left(X^{1} \Sigma_{\mathrm{g}}^{+}\right)$laser induced fluorescence spectrum using the $(0,0),(1,1)$ and $(2,2)$ bands of the $\left(\mathrm{D}^{1} \Sigma_{\mathrm{u}}^{+}-\mathrm{X}^{1} \Sigma_{\mathrm{g}}^{+}\right)$Mulliken system with helium as carrier gas; panel (c): experimental spectrum; panel (d): the best-fit simulation (see text).

Figure $4 \quad \mathrm{CN}\left(\mathrm{X}^{2} \Sigma^{+}\right)$laser induced fluorescence spectrum using the $(0,0),(1,1),(2,2)$ and $(3$, 3) bands of the $\left(\mathrm{B}^{2} \Sigma^{+}-\mathrm{X}^{2} \Sigma^{+}\right)$system with helium as carrier gas; panel (a): experimental spectrum; panel (b): the best fit simulation (see text); panels (c) and (d): enlargement of panels (a) and (b), respectively, showing clearly the overlap of the $(0,0)$ and $(1,1)$ bands and their corresponding band heads.

Figure 5 (a) $\mathrm{CN}\left(X^{2} \Sigma^{+}, \mathrm{v}=0\right)$ rotational distribution. (b) $\mathrm{CN}\left(X^{2} \Sigma^{+}\right)$vibrational distribution, corresponding to a vibrational temperature of $6500 \mathrm{~K}$ (see text).

Figure 6 Laboratory angular distributions recorded at $m / z=51$ for the reaction $\mathrm{CN}+\mathrm{C}_{2} \mathrm{H}_{2}$ at $E_{c}=48.1 \mathrm{~kJ} \mathrm{~mol}^{-1}$. Error bars, when visible outside the dots, represent \pm 1 standard deviation from the 
Figure 7 Time-of-flight distributions of the products (open circles) detected at $m / z=51$ for the reaction $\mathrm{CN}+\mathrm{C}_{2} \mathrm{H}_{2}$ at $\mathrm{E}_{\mathrm{c}}=48.1 \mathrm{~kJ} \mathrm{~mol}^{-1}$ at the indicated $\mathrm{LAB}$ angles. Solid lines represent the TOF distributions calculated from the best-fit CM functions reported in figure 8.

Figure 8 Best-fit CM product (top) angular and (bottom) translational energy distributions for the reaction $\mathrm{CN}+\mathrm{C}_{2} \mathrm{H}_{2}$ at $\mathrm{E}_{\mathrm{c}}=48.1 \mathrm{~kJ} \mathrm{~mol}^{-1}$. The arrows in the bottom panel indicate the total energy available to the products for different vibrational levels of reacting $\mathrm{CN}$.

Figure 9 Laboratory angular distributions recorded at $m / z=65$ for the reaction $\mathrm{CN}+\mathrm{CH}_{3} \mathrm{CCH}$ at $E_{c}=38.4 \mathrm{~kJ} \mathrm{~mol}^{-1}$. Error bars, when visible outside the dots, represent \pm 1 standard deviation from the mean. The circles in the Newton diagram delimit the maximum velocity that the $\mathrm{CH}_{3} \mathrm{CCCN}$ (dashed), $\mathrm{CH}_{2} \mathrm{CCHCN}$ (dotted) and $\mathrm{HCCCN}$ (dash-dotted) products from channel (2a), (2b) and (2c), respectively, can attain if all the available energy is channelled into product translational energy. The solid line is the total $\mathrm{N}(\Theta)$ calculated when using the best-fit $\mathrm{CM}$ angular and translational energy distributions of figure 11 .

Figure 10 Time-of-flight distributions of products (open circles) detected at $m / z=65$ for the reaction $\mathrm{CN}+\mathrm{CH}_{3} \mathrm{CCH}$ at $\mathrm{E}_{\mathrm{c}}=38.4 \mathrm{~kJ} \mathrm{~mol}^{-1}$ for the indicated $\mathrm{LAB}$ angles. Solid lines represent the TOF distributions calculated from the best-fit CM functions reported in figure 11. 
Figure 11 Best-fit CM product (top) angular and (bottom) translational energy distributions for the reaction $\mathrm{CN}+\mathrm{CH}_{3} \mathrm{CCH}$ at $\mathrm{E}_{\mathrm{c}}=38.4 \mathrm{~kJ} \mathrm{~mol}^{-1}$. The arrows in the bottom panel indicate the total energy available to the products for different vibrational levels of reacting $\mathrm{CN}$. 


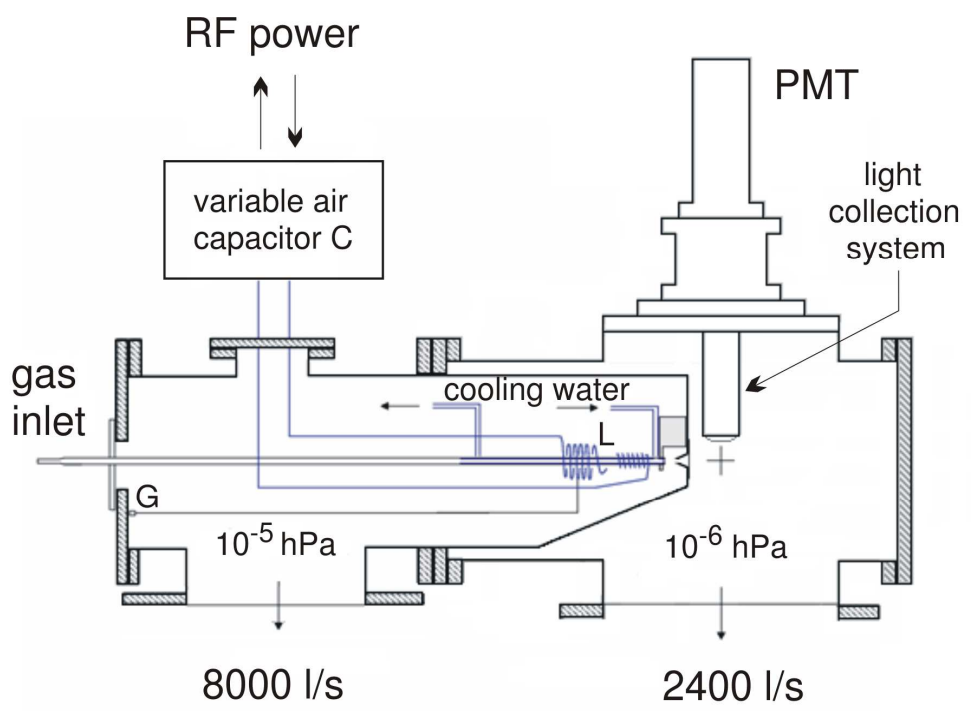

Leonori et al. Figure 1 


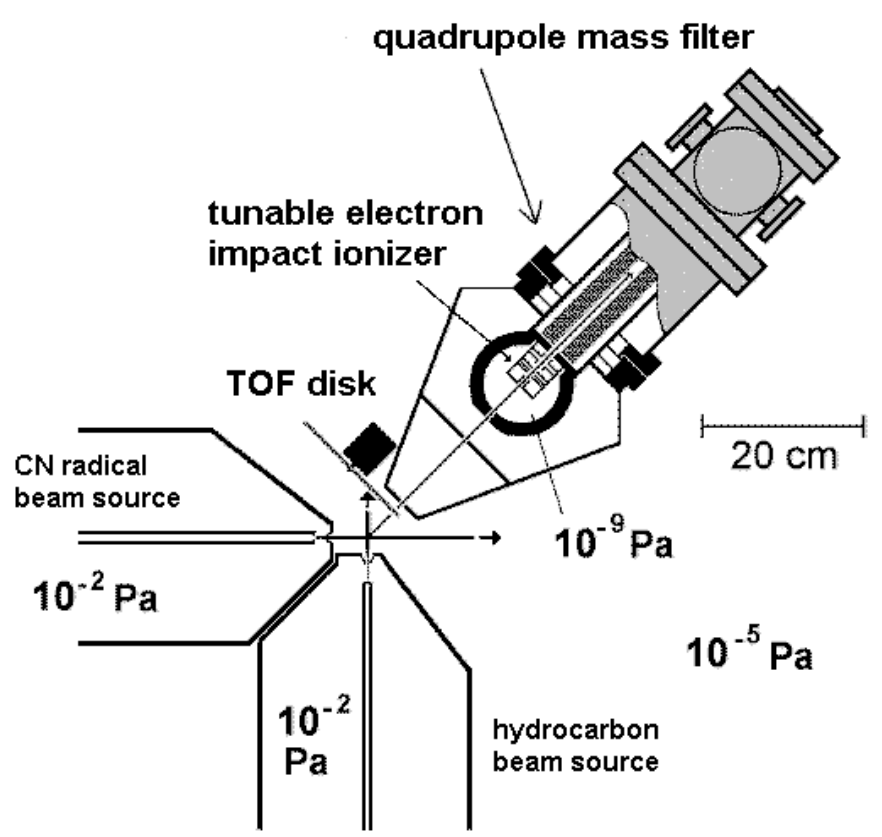

Leonori et al. $\quad$ Figure 2 

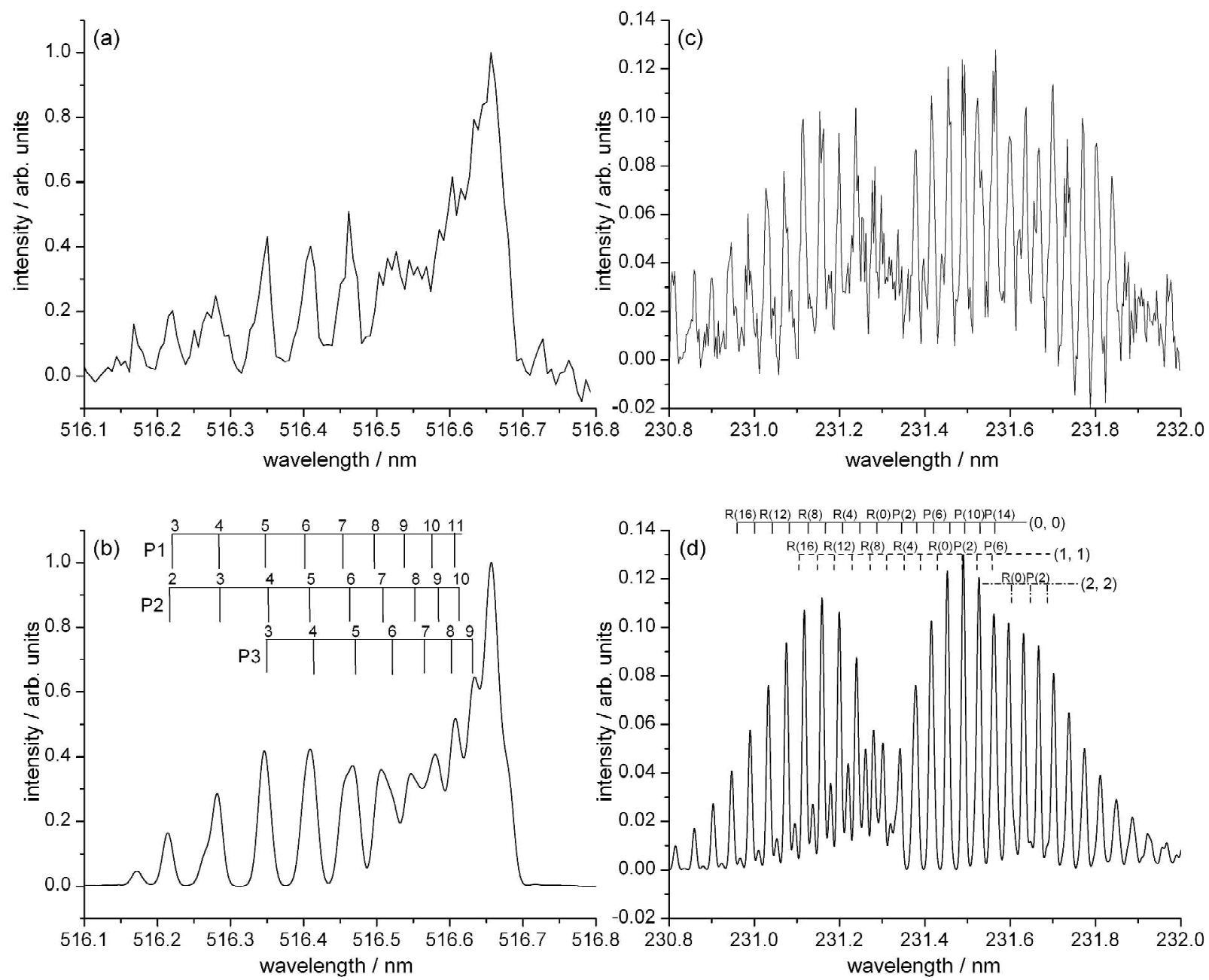

Leonori et al. $\quad$ Figure 3 

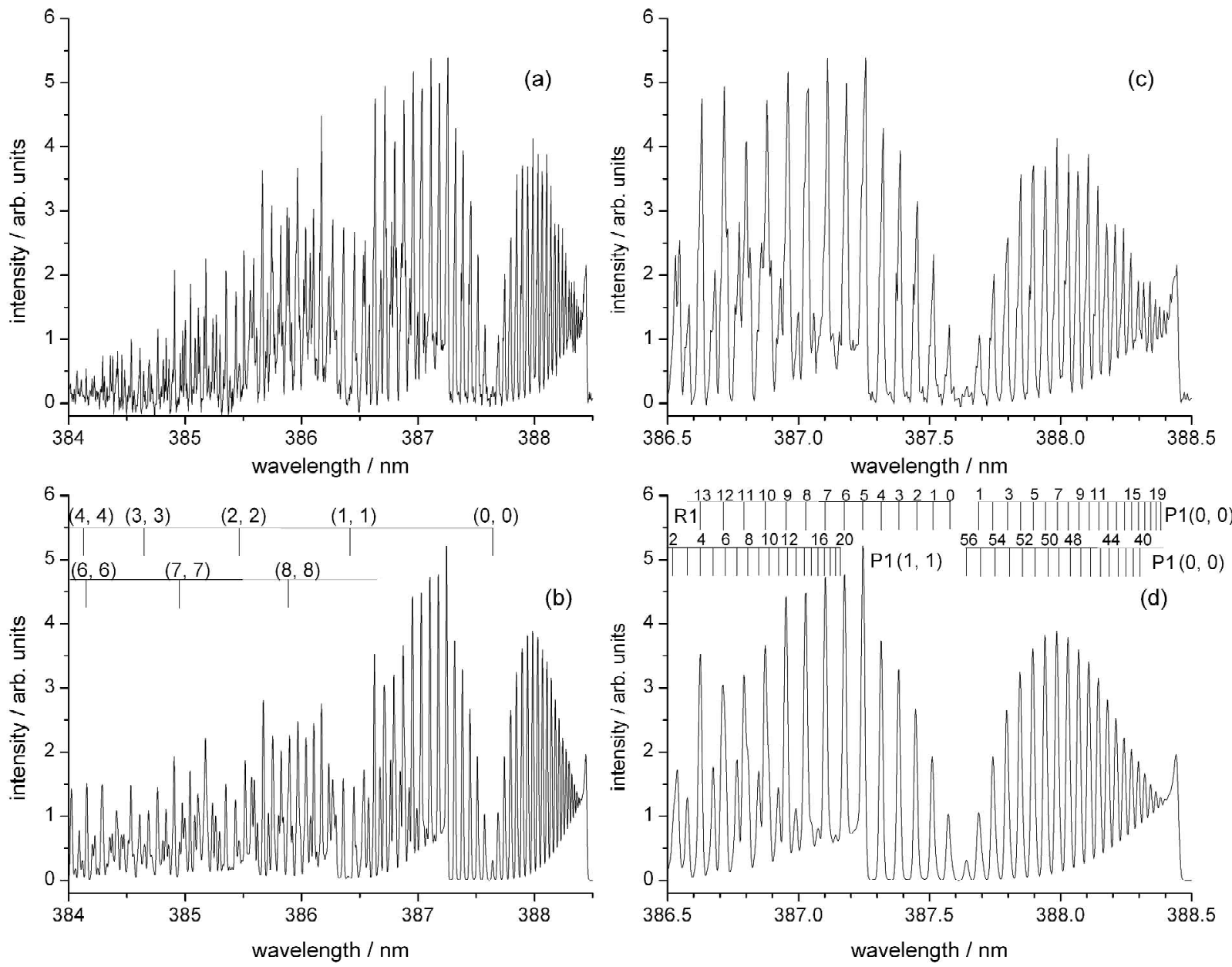

Leonori et al. $\quad$ Figure 4 

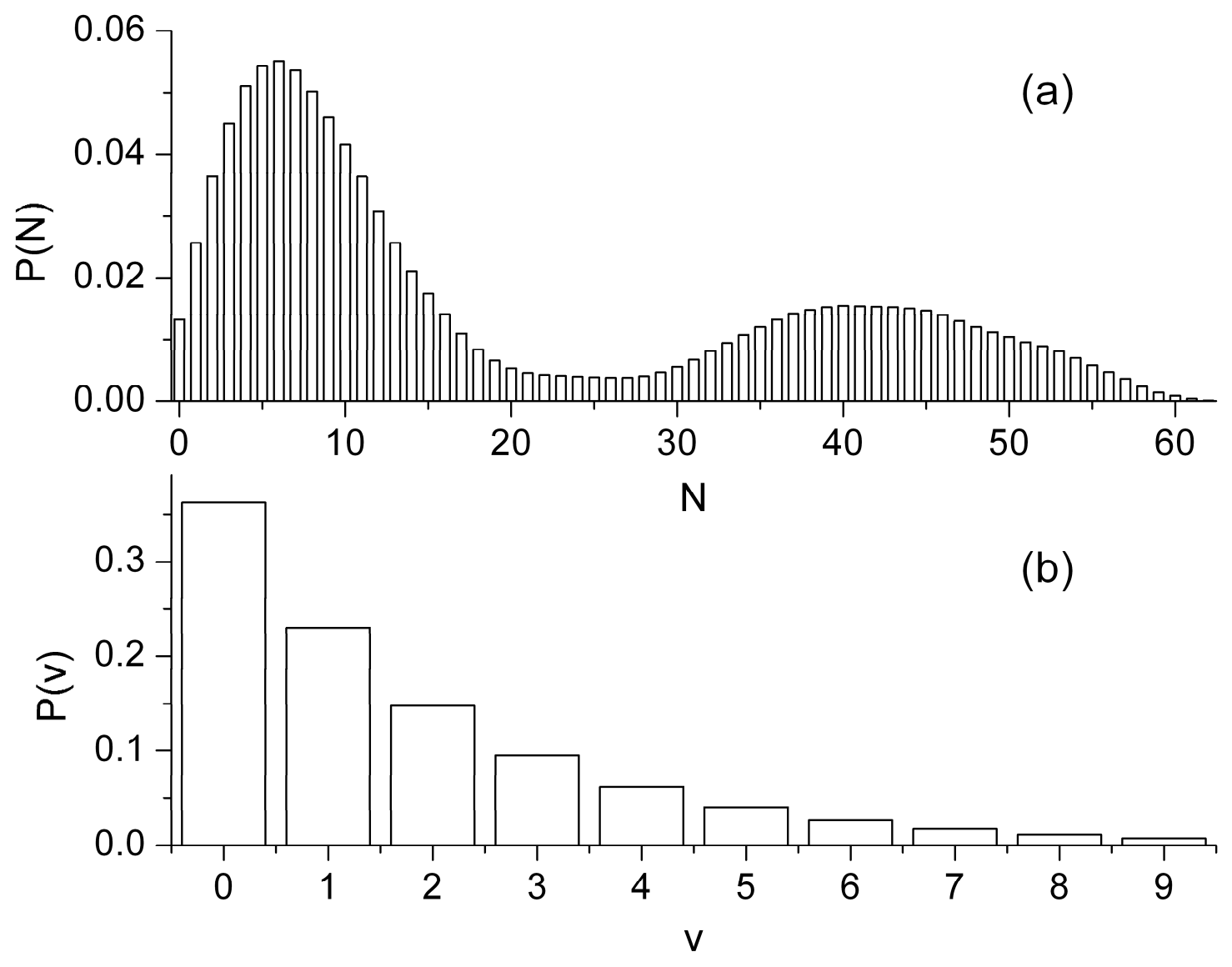

Leonori et al. $\quad$ Figure 5 

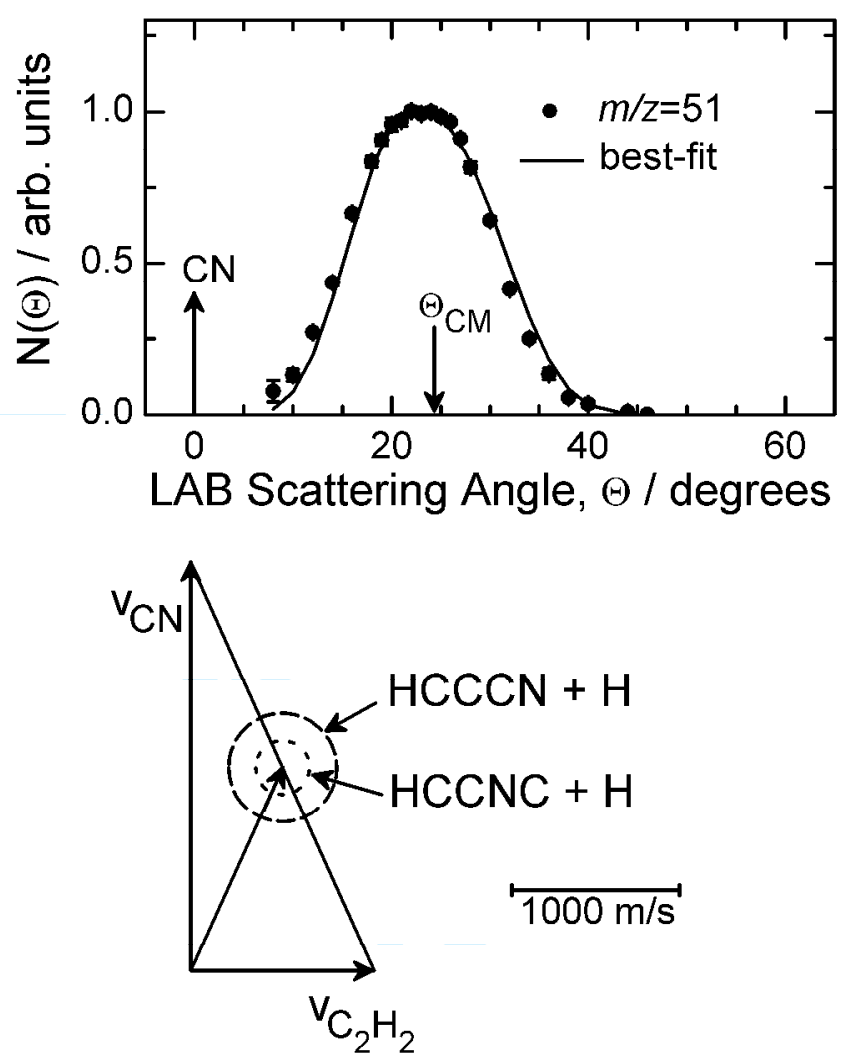

Leonori et al. $\quad$ Figure 6 


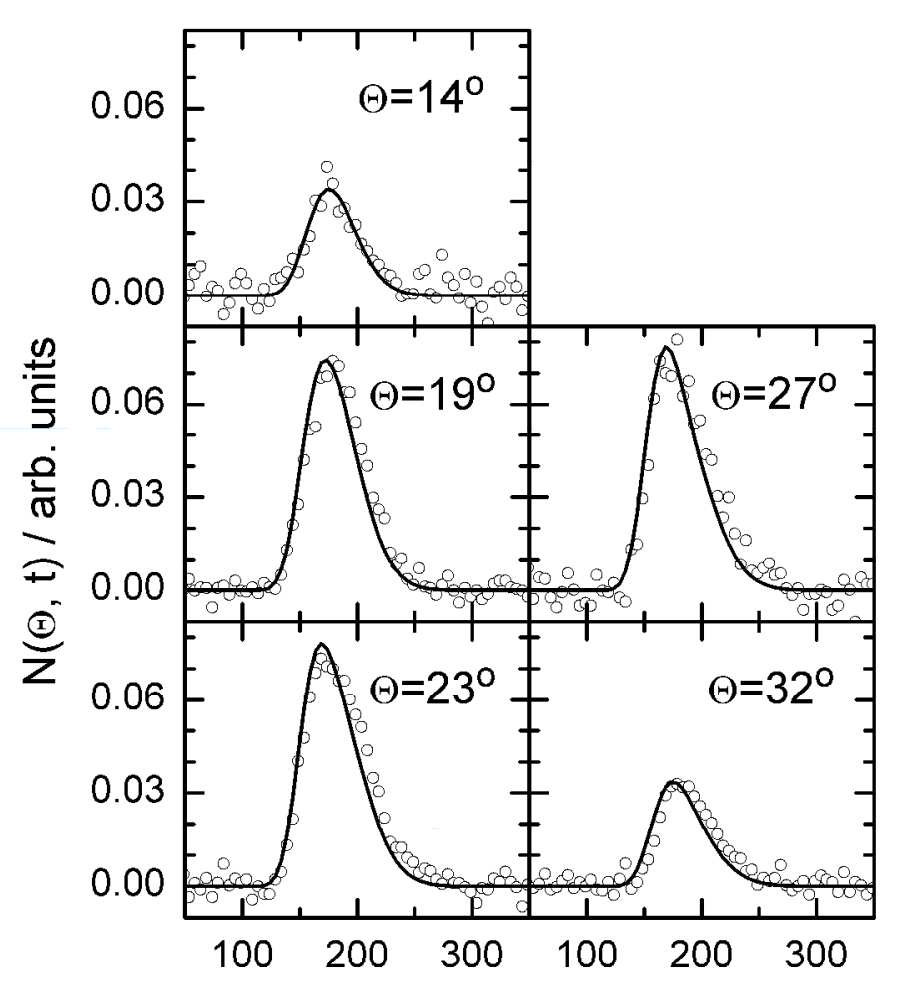

Flight Time, $\mathrm{t} / \mu \mathrm{s}$

\section{Leonori et al. $\quad$ Figure 7}



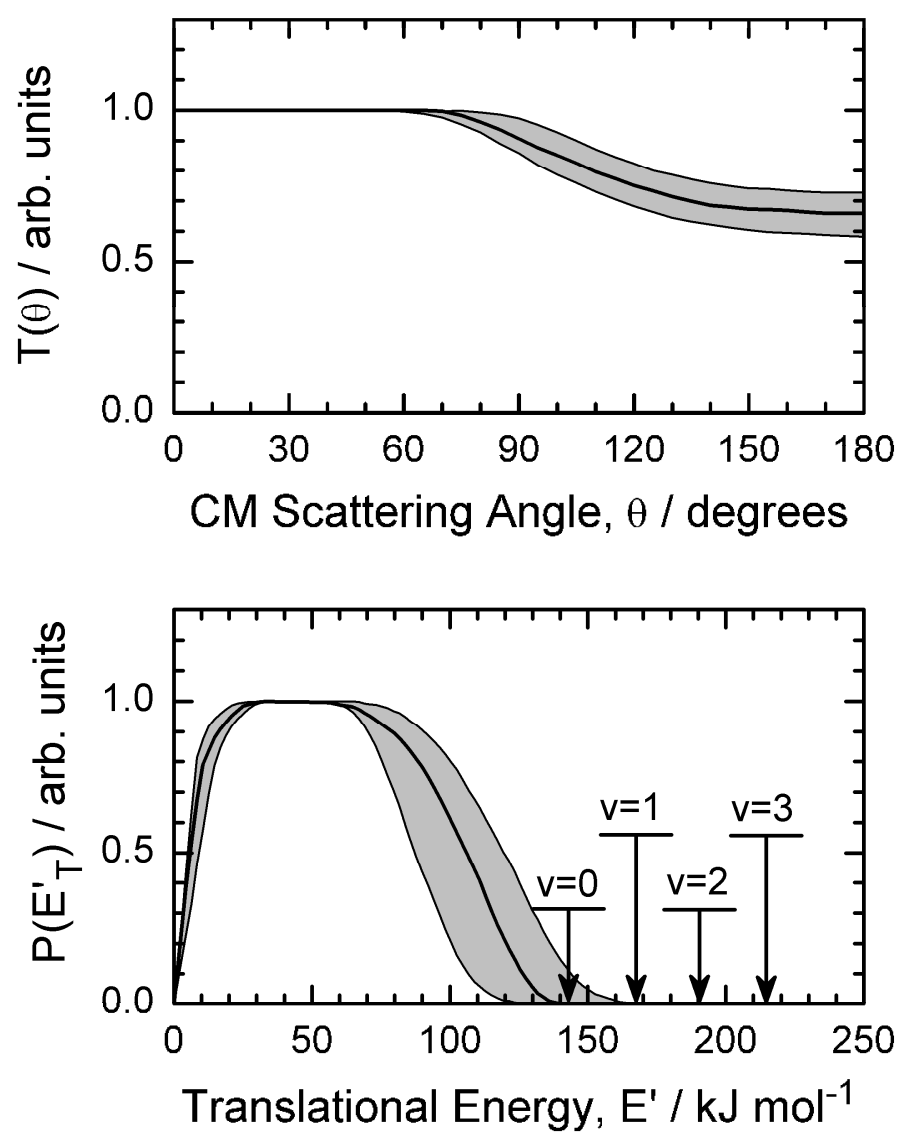

Leonori et al. $\quad$ Figure 8 

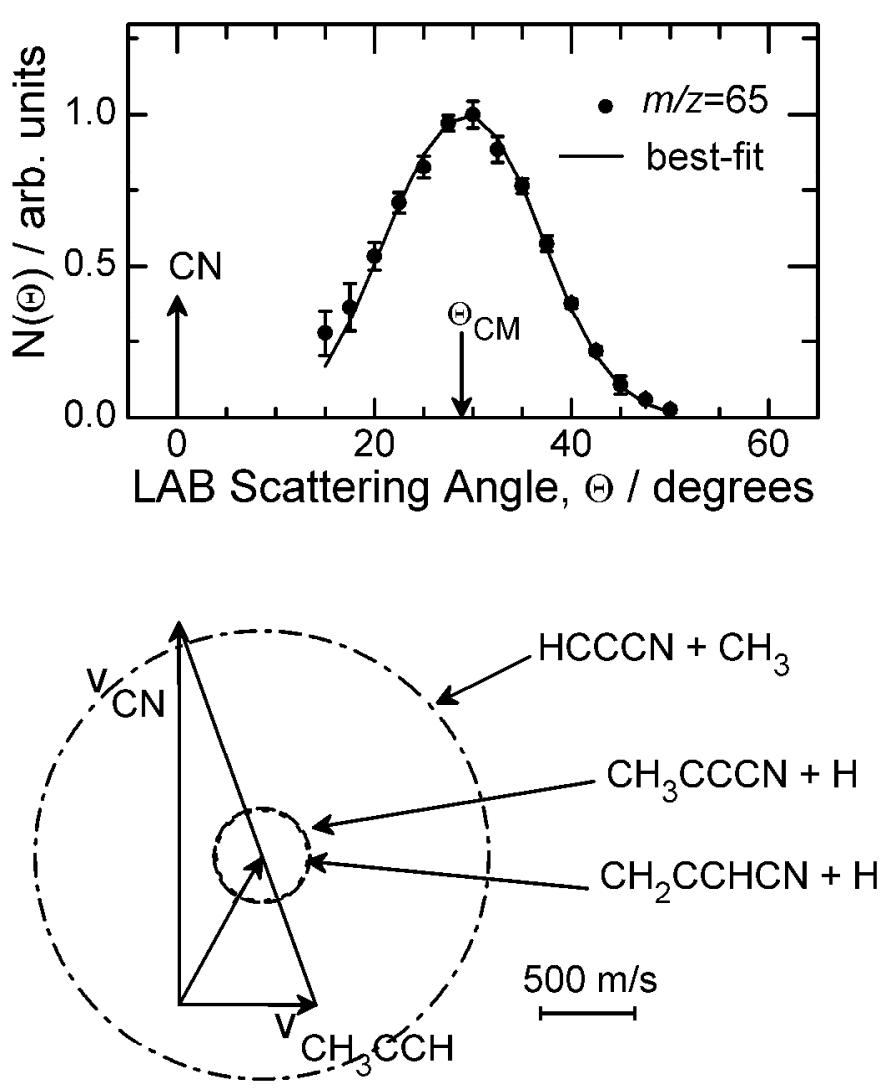

Leonori et al. $\quad$ Figure 9 


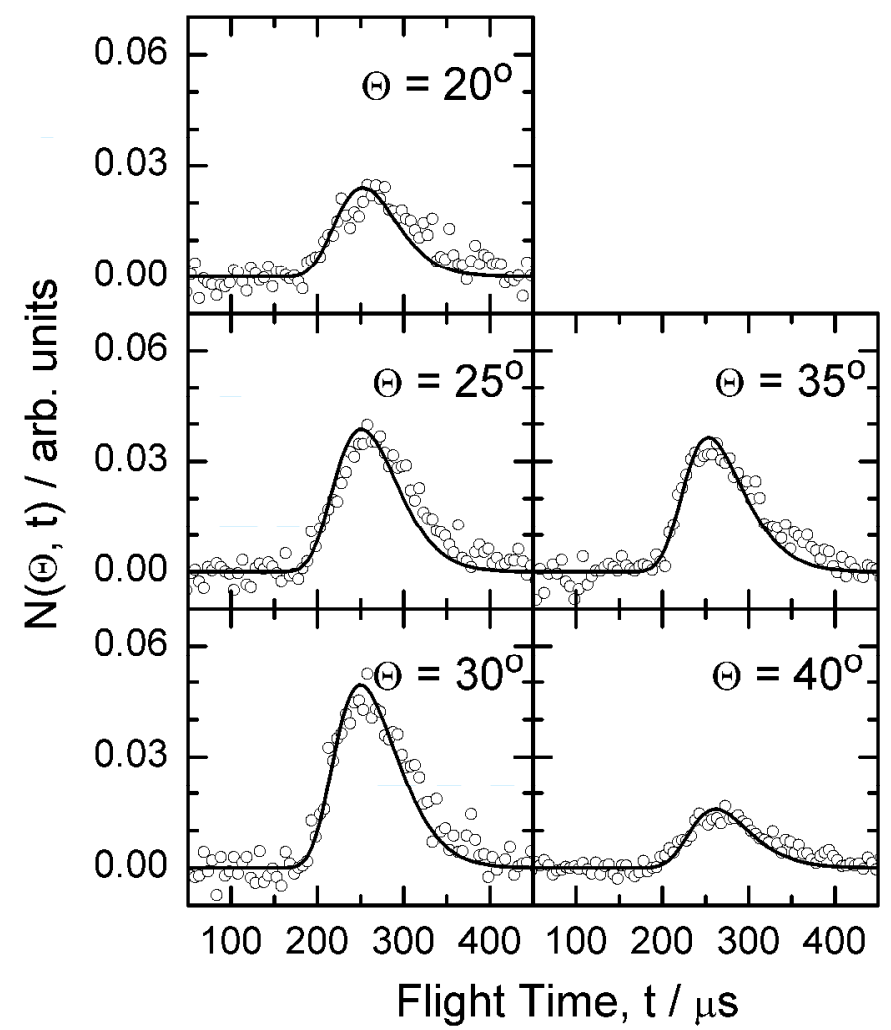

Leonori et al. $\quad$ Figure $\mathbf{1 0}$ 

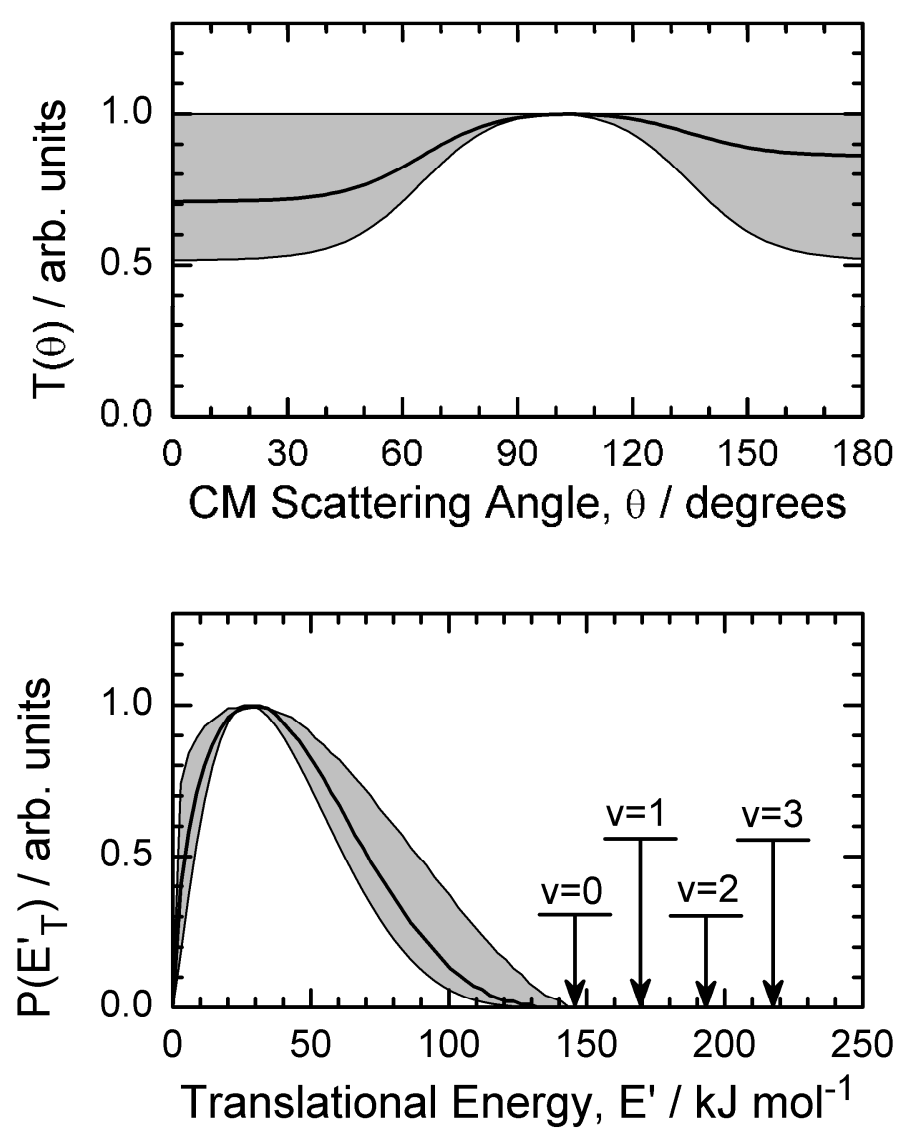

Leonori et al. $\quad$ Figure 11 


\section{REFERENCES}

[1] P. Casavecchia. Rep. Prog. Phys., 63, 355 (2000), and references therein.

[2] Y. T. Lee, J. D. McDonald, P. R. Le Breton, D. R. Herschbach. Rev. Sci. Instrum., 40, 1402 (1969).

[3] Y. T. Lee. In Atomic and Molecular Beam Methods, vol. 1, edited by G. Scoles (Oxford University Press, New York, 1987), pp. 553-568.

[4] R. N. Zare and P. J. Dagdigian. Science, 185, 739 (1974).

[5] J. C. Whitehead. Rep. Prog. Phys., 59, 993 (1996).

[6] S. J. Sibener, R. J. Buss, C. Y. Ng, Y. T. Lee. Rev. Sci. Instrum., 51, 167 (1980).

[7] M. Alagia, V. Aquilanti, D. Ascenzi, N. Balucani, D. Cappelletti, L. Cartechini, P. Casavecchia, F. Pirani, G. Sanchini, G. G. Volpi. Israel J. Chem., 37, 329 (1997).

[8] P. Casavecchia, G. Capozza, E. Segoloni, F. Leonori, N. Balucani, G. G. Volpi. J. Phys. Chem. $A, \mathbf{1 0 9}, 3527$ (2005).

[9] N. Balucani, L. Beneventi, P. Casavecchia, G.G. Volpi, E.J. Kruus, J.J. Sloan. Can. J. Chem., 72, 888 (1994).

[10] N. Balucani, D. Stranges, P. Casavecchia, G.G. Volpi. J. Chem. Phys. 120, 9571 (2004).

[11] N. Balucani, L. Cartechini, M. Alagia, P. Casavecchia, G. G. Volpi. J. Phys. Chem. A, 104, 5655 (2000).

[12] N. Balucani, M. Alagia, L. Cartechini, P. Casavecchia, G. G. Volpi, K. Sato, T. Takayanagi, Y. Kurosaki. J. Am. Chem. Soc., 122, 4443 (2000).

[13] N. Balucani, P. Casavecchia, L. Bañares, F. J. Aoiz, T. Gonzales-Lezana, P. Honvault, J.-M. Launay. J. Phys. Chem. A, 110, 817 (2006).

[14] D. C. Clary, E. Buonomo, I. R. Sims, I.W.M. Smith, W. D. Geppert, C. Naulin, M. Costes, L. Cartechini, P. Casavecchia. J. Phys. Chem. A, 106, 5541 (2002). 
[15] N. Balucani, G. Capozza, L. Cartechini, A. Bergeat, R. Bobbenkamp, P. Casavecchia, F. J. Aoiz, L. Bañares, P. Honvault, B. Bussery-Honvault, J.-M. Launay. Phys. Chem. Chem. Phys., 6, 4957 (2004).

[16] N. Balucani, L. Cartechini, P. Casavecchia, G.G. Volpi, F. J. Aoiz, L. Bañares, M. Menendez, W. Bian, H.-J. Werner. Chem. Phys. Lett., 328, 500 (2000).

[17] D. Skouteris, H.-J. Werner, F. J. Aoiz, L. Bañares, J. F. Castillo, M. Menendez, N. Balucani, L. Cartechini, P. Casavecchia. J. Chem. Phys., 114, 10662 (2001).

[18] F. Leonori, R. Petrucci, N. Balucani, K. M. Hickson, M. Hamberg, W. D. Geppert, P.

Casavecchia, M. Rosi. J. Phys. Chem. A, 113, 4330 (2009).

[19] F. Leonori, R. Petrucci, N. Balucani, P. Casavecchia, M. Rosi, D. Skouteris, C. Berteloite, S.

D. Le Picard, A. Canosa, I. R. Sims. J. Phys. Chem. A, 113, 15328 (2009).

[20] M. Alagia, N. Balucani, P. Casavecchia, D. Stranges, G. G. Volpi. J. Chem. Phys., 98, 8341 (1993).

[21] P. Casavecchia, N. Balucani, L. Cartechini, G. Capozza, A. Bergeat, G. G. Volpi. Faraday Discuss., 119, 27 (2001).

[22] F. Leonori, R. Petrucci, K. M. Hickson, E. Segoloni, S. Le Picard, N. Balucani, P. Foggi, P. Casavecchia. Planet. Space Science, 56, 1658 (2008).

[23] N. Balucani, F. Leonori, R. Petrucci, K. M. Hickson, P. Casavecchia. Phys. Scripta, 78 058117(9pp) (2008).

[24] M. Alagia, N. Balucani, P. Casavecchia, D. Stranges, and G. G. Volpi. J. Chem. Soc. Faraday Trans., 91, 575 (1995).

[25] N. Balucani, G. Capozza, F. Leonori, E. Segoloni, P. Casavecchia. Int. Rev. Phys. Chem., 25, 109 (2006).

[26] P. Casavecchia, F. Leonori, N. Balucani, R. Petrucci, G. Capozza, E. Segoloni. Phys. Chem. Chem. Phys., 11, 46 (2009). 
[27] F. Leonori, N. Balucani, G. Capozza, E. Segoloni, D. Stranges, P. Casavecchia. Phys. Chem. Chem. Phys., 9, 1307 (2007).

[28] Gas Phase Combustion Chemistry, ed. W.C. Gardiner, Jr., Springer, New York (2000).

[29] N. Balucani. Int. J. Mol. Sci., 10, 2304 (2009); and references therein.

[30] R.I. Kaiser, N. Balucani. Acc. Chem. Res., 34, 699 (2001).

[31] N. Balucani, O. Asvany, L.C.L. Huang, Y.T. Lee, R.I. Kaiser, Y. Osamura, H.F. Bettinger. Astrophys. J., 545, 892 (2000).

[32] J. Luque, J.B. Jeffries, G.P. Smith, D.R. Crosley, J.J. Scherer. Combust. Flame, 126, 1725 (2001).

[33] Handbook of Chemistry and Physics (80th Edition), ed. D.R. Lide, CRC Press LLC (1999).

[34] http://webbook.nist.gov

[35] R.V. Olkhov, I.W.M. Smith. J. Chem. Phys., 126, 134314 (2007).

[36] G. A. G. A. Bethardy, F. J. Northrup, R. G. Macdonald. J. Chem. Phys., 102, 7966 (1995).

[37] G. A. Bethardy, F. J. Northrup, R. G. Macdonald. J. Chem. Phys., 105, 4533 (1996).

[38] L. R. Copeland, F. Mohammad, M. Zahedi, D. H. Volman, W. M. Jackson. J. Chem. Phys., 96, 5817 (1992).

[39] I. R. Sims, J. Q. Queffelc, D. Travers, B. R. Rowe, L. B. Herbert, J. Karthauser, I. W. M. Smith. Chem. Phys . Lett., 211, 461, (1993).

[40] D. Carty, V. Le Page, I.R. Sims, I.W.M. Smith. Chem. Phys. Lett., 344, 310 (2001).

[41] I. W. Smith, B. R. Rowe. Acc. Chem. Res., 33, 261 (2000).

[42] D. L. Yang and M. C. Lin. in Advanced Series in Physical Chemistry, Vol. 6, World Scientific (1995), pp. 164-213, and references therein.

[43] K.L. Gannon, D. R. Glowacki, M.A. Blitz, K.J. Hughes, M.J. Pilling, P.W.. Seakins. J. Phys. Chem. A, 111, 6679 (2007).

[44] N. Choi, M.A. Blitz, K. McKee, M.J. Pilling, P.W. Seakins. Chem. Phys. Lett., 384, 68 (2004). 
[45] A. J. Trevitt, F. Goulay, G. Meloni, D. L. Osborn, C. A. Taatjes, S. R. Leone. Int. J. Mass Spectrom., 280, 113 (2009).

[46] C. Huang, W. Li, A. E. Estillore, A. G. Suits. J. Chem. Phys., 129, 074301 (2008).

[47] L.C.L. Huang, O. Asvany, A.H.H. Chang, N. Balucani, S.H. Lin, Y.T. Lee, R.I. Kaiser, Y. Osamura. J. Chem. Phys., 113, 8656 (2000).

[48] L.C.L. Huang, N. Balucani, Y.T. Lee, R.I. Kaiser, Y. Osamura. J. Chem. Phys., 111, 2857 (1999).

[49] N. Balucani, O. Asvany, R.I. Kaiser, Y. Osamura. J. Phys. Chem. A 106, 4301 (2002).

[50] N. Balucani, O. Asvany, A.H.H. Chang, S.H. Lin, Y.T. Lee, R.I. Kaiser, H.F. Bettinger, P.v.R. Schleyer, H.F. Schaefer III. J. Chem. Phys., 111, 7472(2000).

[51] N. Balucani, O. Asvany, A.H.H. Chang, S.H. Lin, Y.T. Lee, R.I. Kaiser, Y. Osamura. J. Chem. Phys., 113, 8643 (2000).

[52] F. Zhang, S. Kim, R.I. Kaiser, A.M. Mebel. J. Chem. Phys., 130, 234308 (2009).

[53] R. I. Kaiser, J. W. Ting, L.C.L. Huang, N. Balucani, O. Asvany, Y. T. Lee, H. Chan, D.

Stranges, D. Gee. Rev. Sci. Instrum., 70, 4185 (1999).

[54] F. Goulay, D. L. Osborn, C. A. Taatjes, P. Zou, G. Meloni, S. R. Leone. Phys. Chem. Chem. Phys., 9, 4291 (2007).

[55] H. Okabe. Photochemistry of small molecules, John Wiley \& Sons, New York (1978).

[56] This value has been obtained from a re-analysis of the original beam velocity distribution and therefore has to be considered as a slightly revised value with respect to that reported in our previous account (ref. 21) where it was $46.7 \mathrm{~kJ} \mathrm{~mol}^{-1}$.

[57] R. D. Levine, R. B. Bernstein. Molecular Reaction Dynamics and Chemical Reactivity, (New York, Oxford University Press, 1987).

[58] C. Naulin, M. Costes, G. Dorthe. Chem. Phys. Lett., 143, 496 (1988). 
[59] X. Tan. (2004). DIATOMIC, a spectral simulation program for diatomic molecules on Windows platforms, release 1.28.

[60] C. V. V. Prasad, P.F. Bernath. Astrophys. J., 426, 812 (1994).

[61] T. W. Schmidt, G. B. Bacskay. J. Chem. Phys., 127, 234310 (2007) (4 pages).

[62] J. Luque, D. R. Crosley. LIFBASE: Database and Spectral Simulation Program, SRI International, 1995.

[63] S. Hay, F. Shokoohi, S. Calister, C. Wittig, Chem. Phys. Lett., 118, 6 (1985).

[64] G. A. Fisk, J. D. Mc Donald, D. R. Herschbach. Discuss. Faraday Soc., 44, 228 (1967).

[65] W. B. Miller, S. A. Safron, D. R. Herschbach. Discuss. Faraday Soc., 44, 108 (1967).

[66] W. B. Miller, S. A. Safron, D. R. Herschbach. J. Chem. Phys., 56, 3581 (1972).

[67] K. M. Hickson, C. M. Sadowski, I. W. M. Smith. Chem. Phys. Lett., 372, 443 (2003).

[68] D. Skouteris, D.E. Manolopoulos, W.S. Bian, H.J. Werner, L.H. Lai, K.P. Liu. Science, 286, 1713 (1999).

[69] D. J. Rakestraw, K. G. McKendrick, R. N. Zare. J. Chem. Phys., 87, 7341 (1987).

[70] R. Zhang, W. J. van der Zande, R. N. Zare. J. Chem. Phys., 94, 2704 (1991).

[71] X. Liu, C. C. Wang, S.A. Harich, X Yang. Phys. Rev. Lett., 89, 133201 (2002).

[72] N. Balucani, P. Casavecchia, F.J Aoiz, L. Bañares, J.-M. Launay, B. Bussery-Honvault, P. Honvault, Mol. Phys., in press.

[73] R.I. Kaiser, N. Balucani, D.O. Charkin, A.M. Mebel. Chem. Phys. Lett., 382, 112 (2003).

[74] X. Gu, Y. Guo, A. M. Mebel, R. I. Kaiser. J. Phys. Chem. A, 110, 11265 (2006). 